NPS ARCHIVE

1967

CHESBROUGH, G.

\title{
SEA SURFACE TEMPERATURE AS AN INDICATOR OF OCEAN CURRENTS
}

\author{
GEOFREY L. CHESBROUGH
}







\section{SEA SURFACE TEPPERATURE AS AN INDICATOR OF OCHAN CURRENTS}

\section{A Thesis}

\section{By}

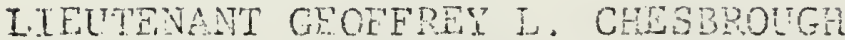
UNITED STAPES NAVY

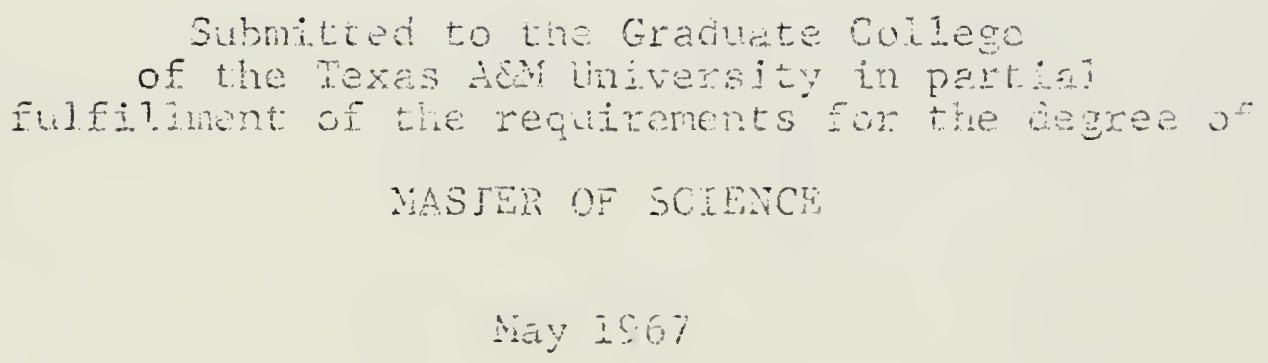


VPS AFCAIVE

$96-1$

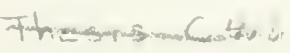

CHESBROUGH, 6 
SEA SURFACE TEMPERATURE AS AN INDICATOR

OF OCEAN CURRENTS

A Thesis

By

LIEUTENANT GEOFFREY L. CHESBROUGH

UNITED STATES NAVY 
ACKNOWLEDGMENTS

The author of this paper wishes to express very special thanks to $\mathrm{Dr}$. Dale F. Leipper for his generous direction of this work.

Sincere gratitude goes to my wife, Mildred, for her understanding, patience, and encouragement.

This thesis was completed under sponsorship by the United States Navy Postgraduate School. 
TABLE OF CONTENTS

Page

ACKNOWLEDGMENTS . . . . . . . . . . . . . . . iii

LIST OF TABLES . . . . . . . . . . . . . . . . vi vi

LIST OF FIGURES . . . . . . . . . . . . . . . . vii

Chapter

I. INTRODUCTION . . . . . . . . . . . . 1

1. Purpose . . . . . . . . . . . . 1

2. Formulation of the Problem . . . . . . 2

II. STATUS OF THE QUESTION . . . . . . . . . 5

III. PROCEDURE . . . . . . . . . . . . 10

1. Data.............. . 10

2. Selection of Areas and Times of Investigation . . . . . . . . . . 10

3. Bathythermograph Cross Sections . . . . 11

4. Diurnal Correction for Sea Surface Temperature Data . . . . . . . . 13

5. Sea Surface Temperature vs. Distance Plots 15

6. Computation of Horizontal Temperature Gradients . . . . . . . . . . 16

IV. DISCUSSION OF RESULTS ........... 18

1. BT Cross Sections . . . . . . . 18

2. Sea Surface Temperature vs. Distance Plots 20

3. Comparison of Horizontal Temperature Gradients . . . . . . . . . . . 24 
Chapter

Page

V. CONCLUSIONS AND RECOMMENDATIONS . . . . . 29

1. Conclusions . . . . . . . . . 29

2. Recommendations ......... . 30 APPENDIX

A. DETERMINATION OF DIURNAL VARIATION OF SEA SURFACE TEMPERATURE IN THE GULF OF MEXICO • • 32

1. Procedure ........... . 32

2. FORTRAN Program ........... 39

3. Directions for Use of the Program . . . . 40

B. EXAMPLE DATA SUMMARY . . . . . . . . 50

C. FIGURES ............... . 51 REFERENCES . . . . . . . . . . . . 82 


\section{LIST OF TABLES}

Table

1. Diurnal variation of the sea surface temperature in the Gulf of Mexico... . . . . . 14

2. Summary of cross current horizontal temperature gradients . . . . . . . . . . . 22

3. Range of diurnal variation of sea surface temperature in the tropics... . . . . . . 33

4. Seasonal change in diurnal range of SST for ocean stations EXTRA and TANGO ...... . 33

5. Number and sources of bucket temperature observations for diurnal variation study . . . 37

6. FORTRAN symbols . . . . . . . . . . 43

7. FORTRAN program . . . . . . . . . . 45

8. Example data sheet for Crossing A-1 . . . . 50 



\section{LIST OF FIGURES}

Figure

Page

1. Three areas indicating location of current cross sections

2. Depth of isotherms of Yucatan Current: Cruise 66-A-11; August $1966(\mathrm{~A}-1)$. . . . . . . 53

3. Depth of isotherms of Gulf Loop Current: Cruise 66-A-11; August 1966 (B-1) . . . . . . . 54

4. Depth of isotherms of Florida Current: Cruise 66-A-11; August $1966(\mathrm{C}-1)$. . . . . . . 55

5. Depth of $22^{\circ} \mathrm{C}$ isotherm across Yucatan Current: Cruise 65-A-16; November 1965 (A-2) . . . . . 56

6. Depth of $22^{\circ} \mathrm{C}$ isotherm across Gulf Loop Current: Cruise 65-A-16; November 1965 (B-2) .

7. Depth of $22^{\circ} \mathrm{C}$ isotherm across Florida Current: Cruise 65-A-16; November 1965 (C-2) . . . . .

8. Depth of isotherms of Yucatan Current: Cruise 66-A-3; February $1966(\mathrm{~A}-3)$. . . . . . . 59

9. Depth of isotherms of Gulf Loop Current: Cruise 66-A-3; February $1966(\mathrm{~B}-3)$. . . . . . . .

10. Deptin of isotherms of Florida Current: Cruise 66-A-3; February 1966 (C-3) . . . . . . .

11. Deptn of isotherms of Yucatan Current: Cruise 64-A-7; May $1964(\mathrm{~A}-4)$. . . . . . . . 62

12. Depth of isotherms of Gulf Loop Current: Cruise 64-A-7; May $1964(\mathrm{~B}-4)$. . . . . . . .

13. Depth of isotherms of Florida Current: Cruise 64-A-7; May 1964 (C-4) . . . . . . . .

14. Crossing A-1: corrected sea surface temperature vs. distance: August 1966 
15. Crossing B-1: corrected sea surface temperature vs. distance: August 1965... . . . . 66

16. Crossing C-1: corrected sea surface temperature vs. distance: August 1966 . . . . . . .

17. Crossing A-2: corrected sea surface temperature vs. distance: November 1965 . . . . . .

18. Crossing B-2: corrected sea surface temperature vs. distance: November 1965 . . . . . .

19. Crossing C-2: corrected sea surface temperature vs. distance: November 1965 . . . . . .

20. Crossing A-3: corrected sea surface temperature vs. distance: February 1966... . . .

21. Crossing B-3: corrected sea surface temperature vs. distance: February 1966 . . . . .

22. Crossing C-3: corrected sea surface temperature vs. distance: February 1966... . . .

23. Crossing A-4: corrected sea surface temperature vs. distance: May 1964 . . . . . . .

24. Crossing B-4: corrected sea surface temperature vs. distance: May 1964 . . . . . . .

25. Crossing C-4: corrected sea surface temperature vs. distance: May 1964 . . . . . . . 76

26. Schematic thermal structure across a current . 77

27. Interpretation of Gulf Loop Current from BT cross section (B-3) winter 1966 ...... . 78

28. (a) Diurnal variation of sea surface temperature for the Gulf of Mexico: summer...

(b) Diurnal variation of sea surface temperature for the Gulf of Mexico: spring and fall............. . . .

(c) Diurnal variation of sea surface temperature for the GuIf of Mexico: winter... 
C H A P T E R I

INTRODUCTION

\section{Purpose}

The need for a means of making ocean current observations that will be both rapid and economical is becoming critical. Contrary to what one might assume, there are many areas of the ocean today that have been inadequately surveyed with respect to currents. Of the approximately 550 Marsden Squares which comprise the world ocean one finds that the mean monthly distribution of current observations amounts to only 3.8 observations per Marsden Square (Engler 1963). When one considers the size of a Marsden Square it is not difficult to visualize how unsatisfactory the state of knowledge of current systems is. To claim a complete understanding based on a mean monthly distribution of only 3.8 observations for every 360,000 square nautical miles is almost shear folly. It would seem that there is hardly sufficient data to locate currents let alone to gain an understanding of any degree of variability of meandering.

The demand for environmental information, especially information on ocean currents, is rapidly increasing. Not only is this information desirable to advance the state of 
man's knowledge about the sea, but also it is desirable and necessary for the defense of this country. As weapons systems and sensors used in the conduct of Anti-Submarine Warfare (ASW) achieve higher and higher degrees of sophistication, environmental information is more and more in demand. Man's knowledge is inadequate to take care of present needs let alone those of the future.

The purpose then of this study is to investigate a means or method for the detection and tracking of current patterns. This method is one which is capable of being used to conduct a survey over a large area with minimum expenditure of funds. It will be explored in the eastern Gulf of Mexico.

2. Formulation of the Problem

A comparison of climatic charts showing the distribution of sea surface temperatures and charts showing surface ocean currents (for example Sverdrup et al. 1942; charts III and VII) shows close correlation between the two. This climatic relationship leads one to believe that there might also exist a similar relationship between synoptic sea surface temperature patterns and the patterns of surface currents existing simultaneously. Geostrophic currents, which have been found to closely approximate most observed ocean flows, require a gradient of mean 
density (averaged over a given depth) across the current. This density gradient implies that there would also be a mean temperature gradient across the current which may, or may not, be reflected in a gradient of the sea surface temperature.

If there is some relationship between surface currents and a gradient of the sea surface temperature, the question that must be answered is, what is the nature of this relationship? This study will thus consist of analyzing sea surface temperatures taken while making perpendicular crossings of currents shown to exist by subsurface data. From these observations then, it is hoped to determine something of the nature of the relationship existing between sea surface temperature patterns and currents. In addition, for specific areas and under specific conditions, the criteria necessary for the detection and tracing of ocean currents using only synoptic sea surface temperature observations will be investigated.

Logically, in order to provide a method for rapid and economical current observations over a wide area, the prime objective of this study will be an attempt to determine the feasibility of using aircraft as data collection vehicles. If it can be assumed that airborne radiation thermometer (ART) data can be correlated with sea surface temperatures taken by conventional means, and also if 
criteria for current detection can be determined, then the aircraft would provide the means by which large areas of the ocean could be rapidly and economically surveyed with respect to currents. 


\section{H A P T E R I I \\ STATUS OF THE QUESTION}

Mariners have known for some time that the temperature of the water in which they sail can be related to their speed of advance. During colonial days, packet ship Masters discovered that by sailing in warm water, the time necessary to make an eastbound crossing of the North Atlantic could be shortened. They also learned that a considerable time savings could be made on the return trip if they avoided the route over which they had come.

Participants in the bi-annual Newport to Bermuda Race have also utilized a knowledge of temperatures of the sea surface in order to cross the Gulf Stream during the course of their race. The rule of thumb which is observed by most of the Bermuda Race sailors is that is the water temperature increases from one observation to the next, their boat is being set to the left. Conversely, a temperature decrease indicates that their boat is being set to the right in the Gulf Stream Counter Current.

One of the first attempts at a detailed current study of a major current was performed by Spilhaus (1940). He made the first investigation of the Gulf Stream with the bathythermograph (BT) and sea sampler. He also described the thermal structure of the Gulf Stream in its 

upper layers. This was perhaps the first interest shown in the study of the Gulf Stream through the means of thermal structure.

Lee (1959; as cited in NAVOCEANO 1963) made a study of the variations in thermal structure of the Norwegian Sea. Lee noted that changed of temperature were observable on the thermograph record and that these changes apparently had some relation to the currents in the sea he was investigating. Fuglister and Worthington (1951) have pointed to the fact that there is a direct relationship between the direction of a current vector and the direction of the isotherms present on a surface map. In $95 \%$ of their observations they found that the current vector was parallel, or nearly so, to the isotherms. Their work was Iimited to the upper 200 meters of the ocean, however, and they apparently made no attempt to directly associate surface temperatures to current patterns.

The Gulf Stream system of unique, strong, well defined currents is an established focus for intensive study. This is a natural result of the Stream's characteristics and its ready accessibility for study by a number of research organizations. Attempts to survey the Gulf Stream have been made by a great number of investigators continuously crisscrossing the current in a single 
ship and determining the thermal structure with a bathythermograph. Iselin and Fuglister (1948) and Ford and Miller (1952) are two such sets of investigators who have attempted this process. Although of great value, their results are incomplete because of the large amount of time required for them to make their observations. During this time the position of the Stream probably shifted, as it is known to do. They admit that because of this shifting some of the desired details were missed. In an effort to eliminate some of the shortcomings of the above approach, Fuglister and Voorhis (1966) suggested another approach to the problem of plotting the Gulf Stream. Their method was to employ a continuous recording device called a "V FIN" which is quite similar to the "NAVITHERM SYSTEY," both of which are manufactured by the Braincon Corp. of Marion, Mass. Again, however, all temperatures and temperature gradients were obtained from the 200 meter level instead of the surface.

The U.S. Naval Oceanographic Office (NAVOCEANO) with its Anti-Submarine Warfare Environmental. Prediction System (ASWEPS) program is producing composite sea surface temperature charts for a given area in the North Atlantic. They are continually improving their analysis technique in order to provide the most accurate synoptic picture of sea surface temperature which is possible. (James 1965; 
1966a; 1966b; NAVOCEANO 1963). The ASWEPS program need for large quantities of synoptic data has brought about the greater use of the aircraft and the airborne radiation thermometer to provide large area coverage in a relatively short time (Peloquin 1963). Gibson (1952), working through NAVOCEANO, has stated that the temperature patterns on composite charts represent the envelopes of the major currents which are responsible for the observed distribution of sea surface temperature. This is perhaps the first indication of an attempt to tie together observations of sea surface temperature and currents. Of the many tests and surveys conducted by NAVOCEANO, one can perhaps best sum up the results by saying that they have shown the ART to be a useful device capable of delineating cold and warm water masses and capable of detecting small horizontal temperature gradients (Wilkerson, Peloquin, and Perlroth 1963). However, it should be noted that NAVOCEANO apparently still has not reported any attempt to determine the exact nature of the relationship between sea surface temperatures and currents.

Even though von Arx and Richardson (1953) believe that the svalidity of using radiant signals from the sea surface for tracing frontal outcrops such as the Gulf Stream front, is open to question, they state that a trustworthy investigation should be made of the relationship 
existing between frontal outcrops detected from the air with those established from shipboard observations. With this in mind, Strack (1953) has made what this writer considers to be the first attempt to bridge the gap between previous work and what needs to be done in order to rapidly survey an oceanic area with the idea of detecting and tracing currents. The work started by Strack should provide a foundation for decision making upon which the question of how and where the more expensive and time consuming process of classical and detailed current studies should be undertaken.

Strack has investigated the Gulf Stream to see if sea surface temperature gradients can be used as a reliable indicator for tracking the current. It is on this point that the present study will also be conducted. If the process of detecting currents by means of sea surface temperature alone is adequate for the Gulf Stream, how well will the same method work on currents of a lesser magnitude? The area of investigation chosen for this study will be the Gulf of Mexico where permanent currents of nearly geostrophic characteristics are known to exist but where the current is of a lesser size and magnitude than is the Gulf Stream. 


\section{H A P T E R I I I}

PROCEDURE

\section{Data}

The data that were analyzed in the conduct of this investigation were obtained from the Department of Oceanography data files of the Texas A\&M University. All data were taken under the supervision of Dr. D. F. Leipper and Professor J. D. Cochrane in conjunction with research projects while aboard the research vessel the R/V ALAMINOS.

The type of data which was sought for this investigation were bathythermograms and their associated bucket temperature observations. In addition to the above mentioned types of data, auxiliary meteorological and thermograph data were used for reference purposes.

2. Selection of Areas and Times of Investigation

For the purpose of this investigation it was decided that a minimum of three current crossings should be investigated in each of the four seasons. It was considered desirable to select three primary areas in which it would be possible to find data for current crossings in each of the four seasons. Thus the three areas chosen on this basis were as shown in figure 1. The first of these three areas, designated by the letter $A$, is considered to be 
an area that would include a crossing of the Yucatan Current. Area $B$ was selected to study the crossings of the northern end of what will be hereinafter referred to as the Gulf Loop Current, and the area including the Florida Current was designated as area $C$. With these designations on the three areas to be studied, each crossing was numbered by adding a numerical suffix representing the season of the year. The number designators are: 1- summer, 2fal1, 3-winter, 4- spring. As an example of the numbering system, current crossing $A-3$ would be a crossing of the Yucatan Current during the winter and crossing $\mathrm{C}-1$ would be the crossing of the Florida Current taken from summer data.

\section{Bathythermograph Cross Sections}

Having chosen which current crossings to investigate, the next step was to isolate the exact position of crossing of each of the currents. To do this, all bathythermograms collected along each of the legs being investigated were arranged in sequential order and read. The information determined from each BT was the depth, in meters, of each of the whole degree Centigrade isotherms. Following this, a BT cross section was plotted for each of the current crossings showing the depth of the isotherms as plotted against distance in nautical miles, along the ships track. 
The ship did not always remain on a straight line course across the currents being investigated. In order to show a straight line crossing on the BT cross section, it was necessary to plot the positions of all of the bathythermograms on a navigational chart, to choose the desired rhumb line, and then to project the positions of the BTs onto this track. It is felt that this is a valid procedure since the amount of error introduced in the representation of the depth of the isotherms from upstream or downstream should amount to no more than a few meters. Having plotted the depths of all of the isotherms at the correct distance along the ships track, straight line segments were used to connect the data points rather than a smooth curve. This was done since there was no apparent reason to assume that the faired curve would be any better representation of the actual thermal structure than that represented by the straight line segments. Bathythermograph cross sections of this type were prepared for each of the crossings with the exception of crossings number $\mathrm{A}-2, \mathrm{~B}-2$, and $\mathrm{C}-2$. For these three crossings, it was considered sufficient to merely represent the thermal structure of the water by the $22^{\circ} \mathrm{C}$ isotherm. These sections are shown in figures 2 through 13.

These BT cross sections were then used to locate the currents. This was done by first making the assumption 
that all of the currents under investigation were geostrophic. It is felt that this is a valid assumption since it is known that most such ocean flows closely approximate geostrophic currents. As explained in Chapter I, these currents, being geostrophic, would display a horizontal gradient of mean temperature since it is known that in the upper layers of the ocean the density of the water is far more dependent upon temperature than it is salinity (Sverdrup et a1. 1942). Location of the currents then is done by finding the area of the maximum inclination of the isotherms. This, then, is the region of the. highest temperature gradient and therefore is the location, or more appropriately, the approximate location of the current.

4. Diurnal Correction for Sea Surface Temperature Data

The length of time required for the ALAMINOS to complete each of the legs which were selected for this study was on the order of 24 hours. If aircraft had been used to cover the same tracks, the time required for each would have been an hour or two at most. Thus in order to eliminate from the observed data that portion of the horizontal temperature gradients due to diurnal variation and in order to correlate as closely as possible the data 
collected by ship with that by an aircraft, it was considered necessary to make corrections to all bucket temperature observations to eliminate the diurnal variation. It was decided that a separate study of the diurnal variation of sea surface temperature should be conducted in the Gulf of Mexico. The values of diurnal variation which were determined are as shown in table 1 . For a complete description of the procedure for determining these values, see Appendix A.

TABLE 1

DIURNAL VARIATION OF THE SEA SURFACE TEMPERATURE IN THE GULF OF MEXICO

\begin{tabular}{lccc}
\hline \hline & \multicolumn{3}{c}{ Diurnal Range, ${ }^{\circ} \mathrm{C}$} \\
\cline { 2 - 4 } Season & Composite & $\begin{array}{c}\text { Wind more } \\
\text { than 14 kts }\end{array}$ & $\begin{array}{l}\text { Wind less } \\
\text { than 10 kts }\end{array}$ \\
\hline Summer & 0.64 & 0.45 & 0.78 \\
Fa11 & 0.45 & 0.25 & 0.50 \\
Winter & 0.31 & 0.22 & $0.59 *$ \\
Spring & 0.40 & 0.31 & 0.50 \\
\hline
\end{tabular}

*Numerical value in question due to insufficient data 
5. Sea Surface Temperature vs. Distance Plots

Having located all of the currents on the BT cross sections, the next step was to plot the sea surface temperature (bucket temperatures corrected for diurnal variation) against the same distance scale as was used for the BT cross sections. These are the plots that will be used to determine the horizontal temperature gradients which may, or may not, be indicative of a current.

As was true for the BT cross sections, straight line segments were used to connect data points on the temperature vs. distance plots. This was done since the nature of bucket temperature observations requires that the observations be separated in space. In this study the bucket observations were separated by distances as great as ten nautical miles or more. This being the case, it was felt that there was not justification for fairing in a smooth curve.

It should be noted in figures 14 through 25 that the plot of sea surface temperature, in some cases, does not correspond in distance to the distance shown on its associated BT cross section. This is true since some of the BT cross sections show a crossing of more than one current and it was considered sufficient to investigate only one such current in each season. Thus the plots of corrected sea surface temperature indicate only a portion of the BT 
cross section as shown by the distance scale on the plots.

\section{Computation of Horizontal Temperature Gradients}

With all of the data thus graphically displayed it was possible to compute the horizontal temperature gradients that existed across currents at the surface and at 100 meters. The 100 meter level was chosen for a comparison level since it has been shown by Strack (1953) that the temperature gradients at this level accurately represent the gradients that exist deeper within the Gulf Stream. If this is true for the Gulf Stream it is felt that it is valid to assume that the same is true for currents being observed in the Gulf of Mexico.

Gradients were determined by first measuring the distances across the currents as shown on the BT cross sections. The absolute value of the temperature difference across the current was found from the surface temperature plots and the gradient determined by division of the temperature difference by the distance.

These gradients were subsequently used to make a comparison of the gradients for all of the seasons. The purpose of this comparison was to determine what, if any, seasonal variation is found. Gradients obtained for the 
various crossings were also compared to test the feasibility of determining the presence of currents by surface temperature gradients alone. 


\section{H A P T E R I V}

DISCUSSION OF RESULTS

\section{BT Cross Sections}

In comparing all of the $\mathrm{BT}$ cross sections, one striking seasonal difference can be seen. The summer BT cross sections show the isotherms to be fairly uniform and the depth of the mixed layer to be rather consistently shallow. The winter sections, on the other hand, show the isotherm patterns to be more irregular particularly near the surface. The winter sections also show that the depth of the mixed layer ranges from very shallow to very deep. Few isotherms are seen to break the surface in the summer while the winter sections show several breaking the surface.

Special attention is called to figure 9 which is the cross section for crossing number B-3. It can be seen that the current selected for study in this section has a rather confused pattern in the surface layer. The current edge is not well defined on the cold water or the left hand side of the current. One interpretation of the current as represented by this cross section is that it is a wide, slow, poorly defined current which perhaps has, incorporated within itself, an eddy or some form of irregular flow. Since a flow pattern of this type is difficult 
to imagine and also because of the extreme width of such a current, as shown, this interpretation is not favored.

An alternative and preferable interpretation of the current pattern as shown in crossing $\mathrm{B}-3$ is that instead of one wide current, there are actually three currents represented by the patterns. The middle current of the three would then be flowing in the opposite direction of the outside two. This would indicate then that the Gulf Loop Current must look something like that shown in figure 27.

Using this latter interpretation, then, horizontal gradients of sea surface temperature were computed three times, one for each of the three currents shown by the section. A fourth gradient, for comparison purposes, was computed across the entire width as indicated by the first interpretation.

It should be noted that in crossing number $\mathrm{C}-3$, shown in figure 10, that the BT cross section does not appear to include the entire current. This appears to be true because one notes that the isotherms commence sloping steeply downward from the very beginning of the observations on this leg. However it should be noted that the depth of the water on the cold water side falls off rapidly, thus, the steep slope of the isotherms may be incluenced by the depth of the water as well as the current. In any 
case it is felt that this would cause no serious error in the calculation of the horizontal temperature gradient.

A general feature of most of the BT cross sections that is worthy of note is the fact that there appears to be a good indicator of the current edge, particularly on the cold water side. On this side the isotherms tend to peak upward just before they begin their steep descent. While this appears obvious for the cold water side of the current, there is no comparable demarkation for the warm water side. Such a phenomenon has been encountered in studies of the Gulf Stream by Ford and Miller (1952). Upon first glance this might be explained as a line of divergence which separates the current from the adjacent waters and which results in a tendency for colder subsurface water to be brought toward the surface. Further comment on this observation will be reserved until the later discussion on a related feature of the sea surface temperature vs. distance plots.

2. Sea Surface Temperature vs. Distance Plots

As previously mentioned, the sea surface temperature plots were used to determine what amount of the cross current mean temperature gradient has been manifested in the gradient of sea surface temperature. The absolute value of the amount of temperature change, as shown in the sea 
surface temperature plots (figures 14 through 25) range from a low of $0.33^{\circ} \mathrm{C}$ in the summer for crossing $\mathrm{C}-1$, to a high of $4.57^{\circ} \mathrm{C}$ for crossing B-3 curing the winter season. A quick comparison of the seasons shows definitely that the amount of temperature change experienced when crossing a current in the winter is the largest of all seasons, and that during the summer one will experience the smallest temperature change while traversing a current. A summary of the values of the temperature change for all of the current crossings is given in table 2 .

A feature of interest shown on some of the plots of sea surface temperature is the existence of a narrow band or surface filament of cold water existing within the current. This is thought to be a surface indication related to the peaking of the isotherms which was observed in the BT cross sections. This phenomenon is noticable during both fall and winter crossings of the Yucatan and the Gulf Loop Currents but not the Florida Current.

A similar observation has been made previously by Ford, Longard, and Banks (1952) in the Gulf Stream and by Cochrane (1966) in the Yucatan Current. These two different papers, however, give differing views as to the cause of this phenomenon. Ford et al. accounts for this layer of cold water as the result of cold, low salinity; subsurface shelf water that has mixed with the water of 


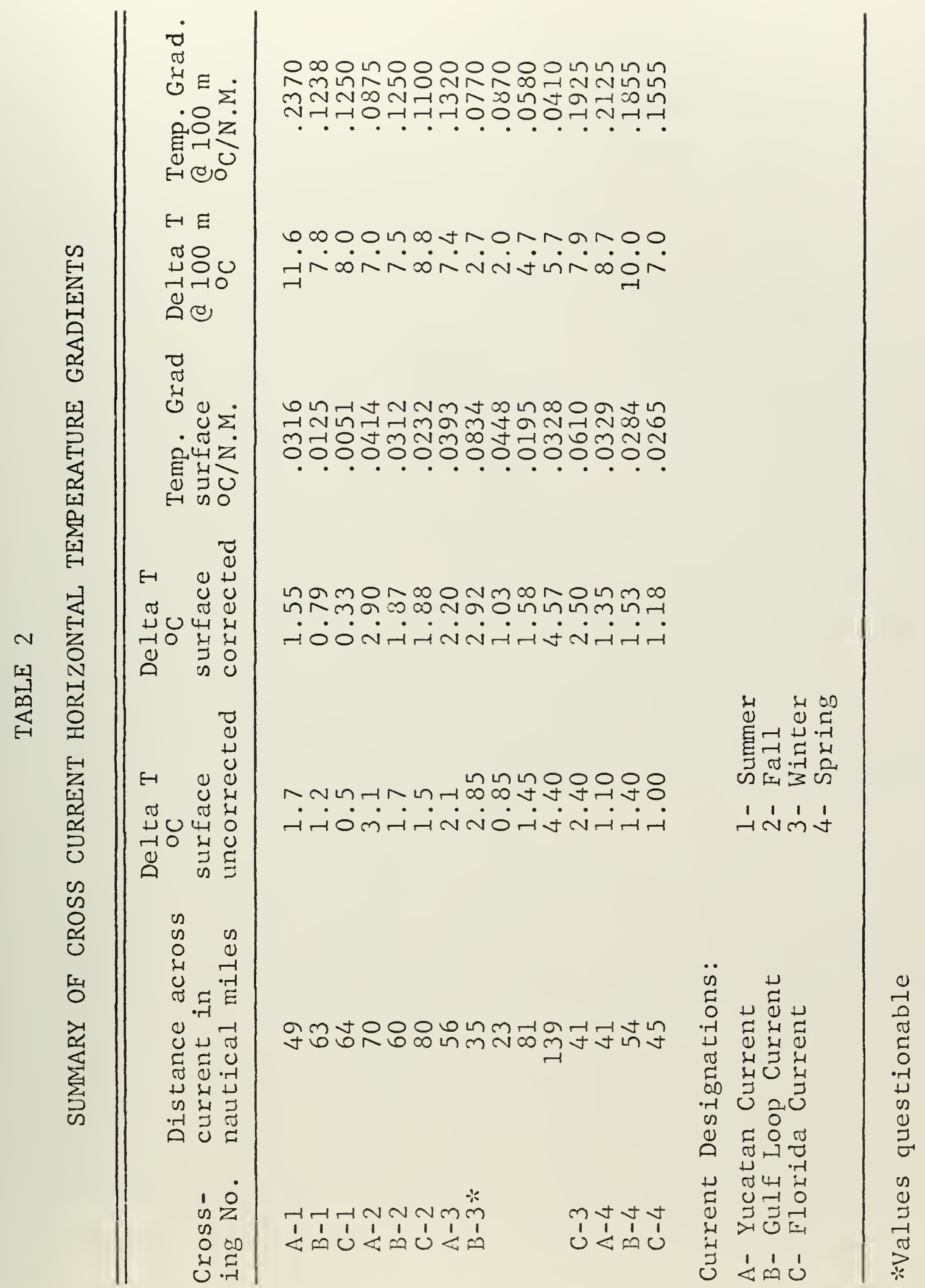


the current proper and has formed a product that is markedly different from either. Ford et al. also state that this water, when appearing, is always at or near the cold water edge of the current. Cochrane, on the other hand, did not find any source of cold, low salinity water by which he could explain his observation and thus attributed the occurrence to be the result of a divergence line. For this investigation it is thought that the mixing process must play some part in the occurrence since the data indicate that the cold band becomes less distinct downstream, and is not observable at all in the crossings of the Florida Current. Therefore it is thought that as the Yucatan Current comes under the influence of the continental shelf off the Yucatan Penninsula, it must, through mixing, pick up a supply of cold water which tends to come to an equilibrium temperature with the surrounding water during downstream travel.

Due to the straight line segment method of construction of the sea surface temperature vs. distance plots, some of the detail of the surface temperature picture was 1ost. Thus in the analysis of these plots, reference was niade to the thermograph record obtained during each of the crossings. The existence of the cold filament is more pronounced on such records as is the temperature pattern of the surface shown in more detail. The thermograph 
traces appear to give a clearer indication of a current. The temperature fluctuations are quite complex while in a current whereas the record is smooth while in slack water. This is taken to be an indication that turbulence and mixing processes are taking place within the current.

Even though, as has been mentioned, the thermograph record is more detailed due to its continuous recording nature, it was not utilized exclusively in this study but used only as a reference in conjunction with the sea surface temperature vs. distance plots. The thermograph traces were not used exclusively because it was felt that the bucket temperature observations directly at the surface would more closely approximate the values of the simulated aircraft type data than would the thermograph whose sensing element is located at a depth of approximately eleven feet. The loss of detail in using bucket temperatures is acceptable so long as the thermograph traces are available for reference.

\section{Comparison of the Horizontal Temperature Gradients}

The final step in the analysis of the data for this problem consisted of comparing the horizontal thermal gradients computed for each of the cross current transits. A summary of these results is given in table 2 . The 
abnormally small values of some of the horizontal temperature gradients observed at 100 meters can be explained by the fact that, in each case, as seen in the BT cross section, the mixed layer depth extended below 100 meters. Therefore, at these places the gradient of temperature at 100 meters would not accurately represent the characteristic temperature gradient across the entire current. In general it can be stated that the sea temperature gradient existing at 100 meters is between eight and ten times greater than that at the surface.

It is interesting to note that for crossing B-3, which was mentioned previously as having a confused pattern of isotherms and which was expected to have a low temperature gradient when the entire width of the current was considered, actually had a relatively high temperature gradient. This is taken as evidence that even if the first interpretation is correct and an extremely wide current exists, the thermal structure of the water during the winter season will still yield a temperature change across the current of sufficient magnitude to be easily observà̉le.

In order to show that the horizontal temperature gradients found for each of the seasons were actually indicative of the currents studied, it is of course necessary to show that no horizontal temperature gradients, through 
comparable distances, can be found to exist except in the presence of currents. In reviewing the bucket temperature data from approximately 10,500 nautical miles of ships tracks it was found that in areas other than those of the Loop Current that the temperature change through a comparable distance amounted to normally no more than 0.2 to $0.4^{\circ} \mathrm{C}$. The maximum sea surface temperature changes in these other areas for the four seasons was found to be: summer- $0.75^{\circ} \mathrm{C}$, fall- $0.62^{\circ} \mathrm{C}$, winter- $0.51^{\circ} \mathrm{C}$, and spring- $0.65^{\circ} \mathrm{C}$.

The inference to be drawn from the above is that during the summer, slack water temperature gradients may be nearly equal to the temperature gradients associated with the currents. Thus, during the summer months it would apparently prove fruitless to attempt to trace current patterns by this method. During the fall and winter, on the other hand, the sea surface temperature change associated with the currents is sufficiently greater than any expected sea surface temperature change in slack water. Therefore it appears that sea surface temperature would be a good indicator of currents in these seasons. During the spring, the reliability of this system would be questionable.

These results appear reasonable when one considers the nature of the thermal structure seasonal changes. 
Consider the schematic representation as shown in figure 26 (a) which would be typical of a summertime situation. During the summer one finds a relatively shallow mixed layer, a strong thermocline, and stable conditions predominating. In moving from position A to $B$ in figure 26 (a), one can see that the water at the surface is still basically the same temperature. Autumnal cooling and the usually stronger winds that prevail during this season will break down the stability of the upper layers and allow mixing to extend to greater depths. One can now see that at position $B$ in figure 26 (b) that even though the depth of the mixed layer has increased, water of nearly the same temperature has been mixed. At position A on the other hand, the mixing involves water of a temperature difference, delta $\mathrm{T}$, and the resulting surface water temperature should be lower after mixing. The resultant of this process would then look like figure 26 (c), characteristic of mid-winter conditions. Now an observer moving from position A to B would notice a large change in sea surface temperature in relation to the current.

The results of this study agree quite favorably with those of Strack (1953). Strack has found that in 99 crossings of the Gulf Stream, only 17 times did the sea surface temperature fail to reflect the changes occurring deeper within the current. In all 17 cases where he was unable 
to show any correlation between changes in sea surface temperature, the data had been collected during the summer months. Strack's conclusions were that the horizontal temperature gradients were reliable indicators of the Gult Stream during the winter months only. The nature of the surface temperature changes with respect to currents also concurs with the work of Church (1937; as cited in Ford et al. 1952). 


$$
\text { C H A P T E R } \mathrm{V}
$$

CONCLUSIONS AND RECOMMENDATIONS

\section{Conclusions}

From the results shown by the sea surface temperature vs. distance plots, it is concluded that, in traversing any one of the currents investigated, there is an observable change in sea surface temperature which is associated with the current. This change is such that if one were to observe an increase in the sea surface temperature the direction of the current would be to the observer's left as he faced across the current. Conversely, the current would be to the observer's right if a temperature decrease were observed.

Further it is concluded that this observable change in sea surface temperature associated with the currents used for this investigation has a seasonal variation. This variation is such that it can reasonably be expected to detect the presence of these currents in the Gulf of Mexico using only sea surface temperature data during the fall and winter seasons.

Based on the capabilities of the ART (Peloquin 1961; 1963), and upon the magnitude of observable horizontal sea surface temperature gradients, as determined by this 
study, it is further concluded that it would be feasible to use an aircraft equipped with an ART for large area current surveys in the Gulf of Mexico during the fall and winter months.

\section{Recommendations}

It has been shown here and by Strack that it is feasible to use sea surface temperature gradients to detect and track currents in two specific areas of the ocean during the fall and winter. It is recommended that further studies be conducted in other regions of the ocean to determine the feasibility of using aircraft to trace currents in all areas of the ocean. It is also felt that additional studies should be conducted using an aircraft as the data collection vehicle. In these studies it would be desirable to have simultaneous data collected by surface ships in order to provide a ground truth for the airborne data.

If the state of knowledge can be brought to the point where currents can be reliably tracked world wide by the use of sea surface temperature data, it would be desirable to conduct studies leading toward the direct computation of geostrophic currents based on aircraft collected data. The ground work on this subject has already been provided by the work of Stommel (1947) and La Fond 
(1949) who have suggested means of estimating geostrophic currents from bathythermograph data. James (1966c) has gone a step further by suggesting a method whereby a nomagram is prepared on the basis of a good T-S relationship which is characteristic of an area and empirical relationships. This nomagram is then utilized to estimate the geostrophic current based solely on the observations of horizontal sea surface temperature gradient.

Another subject for possible further study concerns the observations made in this study and by others, of the existence of the filament of cold water appearing at the surface within some of the currents. It is recommended that a study be conducted in the Gulf Loop Current, utilizing thermograph traces, which will trace the band of cold water upstream and attempt to determine the origin of the cold water.

Additionally, it is recommended that the FORTRAN program written for this study be used for a continuing study of diurnal variation of sea surface temperature under various conditions. 
APPENDIX A

DETERMINATION OF DIURNAL VARIATION OF SEA SURFACE TEMPERATURE IN THE GULF OF MEXICO

\section{Procedure}

The work of previous investigators on dirunal variation of sea surface temperature was not considered adequate to describe the variation in the Gulf of Mexico in the required detail necessary for this study. Sverdrup et al. (1942) has shown a diurnal variation for the topics (see table 3 ), however he states that the numerical values given are questionable. Koizumi (1956; as cited Roll 1965) has also completed a study on diurnal variation in the Pacific but his work was in higher latitudes than those encountered in the Gulf (see table 4). The detail in the description of diurnal variation that was considered desirable for this study consists of the diurnal variation for each season of the year, and within each season, the diurnal variation when the wind is stronger than $14 \mathrm{kts}$ as well as for winds less than $10 \mathrm{kts}$. For this reason it was considered necessary to conduct a new. study to determine the diurnal variation of the Gulf of Mexico.

Obviously, the most practical means by which one should attempt to determine the diurnal variation is to 
TABLE 3

RANGE OF DIURNAL VARIATION OF SURFACE TEMPERATURE IN THE TROPICS

(Table 32 Sverdrup et a1. 1942)

Wind and Cloudiness

1. Moderate to fresh breeze
a. Sky overcast
b. Sky clear
0.39
0.71
0.60
1.10
0.0
0.30

2. Calm or very light breeze
a. Sky overcast
b. Sky clear
0.93
1.40
1.90
0.60
1.59
1.20

\section{TABLE 4}

SEASONAL CHANGE IN DIURNAL RANGE OF SST

FOR OCEAN STATIONS EXTRA AND TANGO

(after Koizumi 1956)

\begin{tabular}{|c|c|c|c|c|}
\hline \multirow[b]{2}{*}{ Station } & \multirow[b]{2}{*}{ Position } & \multicolumn{3}{|c|}{ Diurnal Range, ${ }^{\circ} \mathrm{C}$} \\
\hline & & $\begin{array}{l}\text { Annual } \\
\text { Avg. }\end{array}$ & Winter & Summer \\
\hline EXTRA & 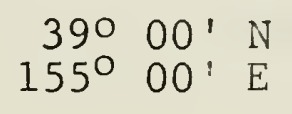 & 0.28 & 0.14 & 0.54 \\
\hline TANGO & $\begin{array}{rll}29^{\circ} & 00^{\prime} & \mathrm{N} \\
135^{\circ} & 00^{\prime} & \mathrm{E}\end{array}$ & 0.45 & 0.30 & 0.67 \\
\hline
\end{tabular}



obtain data from a fixed station. This type of data is available for only one location in the Gulf, but this source is not considered adequate for this work. The NOMAD buoy in the Gulf gives the sea surface temperature only in half degree centigrade increments. Other data available consists of bucket temperature observations taken from a moving ship. This has the disadvantage that one is not always measuring the temperature of the same water mass, and the temperature changes noted would not only be due to diurnal variation but also due to the temperature of the different water masses, and also due to the local effects of upwelling, river outflow, and currents. In addition to the effects of the moving platform on the range of diurnal variation, changes in local apparent time due to changes in longitude will effect the time of the daily maximum and minimum temperatures. Since the gulf of Mexico is approximately $15^{\circ}$ of longitude wide, the change in local apparent time would be approximately one hour for a complete crossing of the Gulf. Thus it was necessary to assume the Gulf of Mexico to be a large pool of water having essentially the same sea surface temperature everywhere and that any anomalous temperatures would be due to the above described effects of the moving platform.

The procedure, then, was to take a large quantity of 
data, assuming a random selection, and to find the frequency of occurrence of the temperatures for each hour under specified conditions. The most frequently observed temperature for each hour was then considered as the one which is "normal." The diurnal variation then may be found by using the mode of the distribution curve for each hour. As a check on this procedure, the frequency weighted mean temperature for each hour was also calculated and the diurnal range determined from this information. It was found that by using the frequency weighted mean temperature a smoother curve for the range of diurnal variation was produced.

As described above, the diurnal variation for each of the four seasons was determined and within each season the diurnal variation was determined for the various wind conditions. Winds above $14 \mathrm{kts}$ were considered high winds and those below $10 \mathrm{kts}$ as low. Even though the earlier suggestions that the drag coefficient over water increases abruptly at about the speed of $14 \mathrm{kts}$ is not supported (Deacon and Webb 1962), it is still considered that the ten to fourteen knot dividing zone is meaningful. The linear increase in drag coefficient in this zone (Francis 1951; Malkus 1962) is still sufficient to produce the critical value of drag coefficient necessary to produce whitecaps on the surface and the associated turbulent 
mixing which accounts for a decrease in the observed diurnal range (Mosby 1958; as cited in Roll 1965).

In determining the frequency of occurrence and the frequency weighted mean temperature for each of the categories chosen, a FORTRAN computer program was written (see table 7). This program was utilized to analyze 4,017 observations of the sea surface temperature as taken by a bucket thermometer aboard the R/V ALAMINOS. The breakdown of the number of observations by seasons appears in table 5.

The results of this diurnal variation study show a definite bi-modal distribution of the surface temperatures. This is due to two fundamental reasons. First, the selection of data for this analysis was not truly random because it depended upon ship tracks and upon the nission of the ship during each cruise from which data were taken. The second reason for the bi-modal distribution is that the initial assumption that the Gulf of Mexico is a large pool of water having a nearly constant surface temperature everywhere, is false. In actuality one finds there are two basic water masses in the Gulf which are separated from one another by the currents which cut across the southeastern portion of the Gulf. The cold side corresponds to what is normally called the left hand water, and the warm side of the Gulf corresponds to the right hand 


\section{TABLE 5}

NUMBER AND SOURCES OF BUCKET TEMPERATURE OBSERVATIONS FOR DIURNAL VARIATION STUDY

\begin{tabular}{|c|c|c|c|}
\hline Season & $\begin{array}{l}\text { Cruise } n \\
\text { observat }\end{array}$ & $\begin{array}{l}\text { m which } \\
\text { ected }\end{array}$ & $\begin{array}{l}\text { Number of } \\
\text { observations }\end{array}$ \\
\hline Summer & $\begin{array}{l}65-A-11 \\
65-A-12 \\
65-A-13\end{array}$ & $\begin{array}{l}66-A-11 \\
66-A-12 \\
\end{array}$ & 1,236 \\
\hline Fal1 & $\begin{array}{l}63-A-3 \\
65-A-16\end{array}$ & $66-A-15$ & 633 \\
\hline Winter & $\begin{array}{l}64-A-2 \\
64-A-3 \\
64-A-15 \\
64-A-16\end{array}$ & $\begin{array}{l}65-A-2 \\
66-A-1 \\
66-A-3\end{array}$ & 1,183 \\
\hline \multirow[t]{2}{*}{ Spring } & $\begin{array}{l}64-A-7 \\
64-A-8 \\
65-A-7\end{array}$ & $\begin{array}{l}66-A-6 \\
66-A-7\end{array}$ & 966 \\
\hline & & al & 4,017 \\
\hline
\end{tabular}


water. Research vessels normally search out oceanographic features such as currents and attempt to make transits of them. For this reason one can see how a bimodal distribution can be achieved.

Table 1 summarizes the results of the diurnal variation study. One can see that, as expected, the diurnal variation during the summer months is considerable, while during the winter months it is almost negligible. The effect of wind velocity on the diurnal variation is quite obvious. The main feature is that at high wind velocity the wave motion produces a thorough mixing in the surface layers and allows the incoming solar radiation to be distributed over a much greater volume of water, (deeper mixed layer) leading to a small range of temperature. However, in calm weather the intensive mixing does not take place and the incoming solar radiation is confined to a muc: shallower layer, thus causing a higher range of temparature.

After computation, all of the values found in table 1 were used to correct all bucket temperature observations. By assuming that the diurnal range takes on sinusoidal characteristics, as suggested by Sverdrup et a1. (1942), it was possible to construct a correction graph in the form of a smooth sine curve having an amplitude of one half the value of the diurnal range (see figures 28 (a), (b), and (c)). In this manner the correction factor 
would then have the effect of bringing all observations to a mean value.

\section{FORTRAN Program}

The data used in determining the diurnal variation of sea surface temperature were processed by means of the IBM 709 computer system of the Data Processing Center, Texas A\&M University. The program written for this study (see table 7) is designed to separate the various observations of the sea surface temperature into predetermined zones and to count the number of observations in each of the zones. This allows an output which will give the frequency of occurrence of a particular temperature for each hour of the day. The program will also separate the data in such a manner as to determine, from the same data, the frequency of occurrence under any desired sets of restrictions such as wind conditions or cloudiness. In this manner one can find the frequency of occurrence of the temperature not only for the composite of all data analyzed for a particular period of time but also the frequency of occurrence of the temperature for the same period under any set of restrictions selected.

The output of this program consists of the ICOUNT (explained in the list of FORTRAN symbols; tabie 6) array which gives the number of observations in each of the 
predetermined zones for each hour of the day. The output also includes a listing for each hour of the mode temperature of the distribution curve, the percentage of total observations for a given hour that fall within the zone of the mode temperature, and finally, the frequency weighted mean temperature for each hour.

It is felt that the basic program could be expanded through the use of subroutine or function sub-programs to enable computation of statistical parameters such as standard deviation, skewness, kurtosis, etc. This was not done in this study because the principle idea being investigated was the relationship of surface temperatures to currents and not a statistical study of the dilirnal variation of sea surface temperature.

3. Directions for Use of the Program

1. Place all temperature data on cards using format 8F10.4. This gives 8 hours observations on one card or three cards equal to one day's observations. If any hourly observation was not made place 0.0 in the correct spot on the data card and the program will disregard this hour.

2. Punch the ISEP cards in format 24I1. The numbers used for the hourly separation parameters in this study were: 
0 - use in composite only and not in either of the separated counts

1- use data in composite and also count for wind more than $14 \mathrm{kts}$

2- use in composite and also in the count for wind less than $10 \mathrm{kts}$.

This could have been used to separate by percentage of cloud cover or any other parameter desired. If no separation of the data is desired:

a. Remove the section of the program from the statement:

DO $20 I=1, N$

through the statement:

20 CONTINUE

b. Do not put any ISEP data cards in the deck

c. Replace the statement:

DO $49 \mathrm{KKK}=1,3$

by the statement:

$\mathrm{KKK}=1$

3. Arrange the data cards in the following order:

a. \$DATA

b. A card containing the value of $M$ in columns 1-5 (right adjusted) 
c. A card containing the value of:

i. $M$ in columns $1-5$ format I5

ii. $X$ in columns 6-15 format F10.4

iii. DELTAX in columns 16-25 format F10.4

iv. $N$ in columns 26-30 format I5

d. The data cards for the DAYORA array for the first set of data; the number of cards in this section should equal three times $N$.

e. The ISEP cards for the first set of data; the number of cards in this section should equal $N$.

f. If more than one set of data is to be analyzed, a card containing all of the information similar to card c. above, will be inserted before each of the different sets of data. The values of the variables shown on this card may be different from one set of data to the next. This card will also act as the separator card for the different sets of data.

g. Then place remaining sets of data, alternating the separator card, the DAYORA data, and the ISEP data.

4. This program will require approximately 300 lines of output for each set of data and will require approximately 10 seconds for each 30 days of data to be ana1yzed. 
TABLE 6

FORTRAN SYMBOLS

FORTRAN

ZONE (I)

$\operatorname{DAYORA}(I, J)$

$\operatorname{ICOUNT}(I, J)$

XMODE (I)

$\operatorname{PERC}(I)$

FWMT (I)

$\operatorname{ISEP}(I)$

M

MM
DEFINITION

The array containing the numerical value of the upper limit of each zone chosen for the frequency distribution count.

The array used to store the values of sea surface temperature for each day (DAY) and for each hour (ORA) of the day.

The array used to count the number of occurrences of a temperature in each particular zone.

The array used to store the mode value of temperature for each of the 24 hourly distribution curves.

The array used to store the percentage of observations that occur within the zone from winich XMODE was determined.

The array holding the computed values of the 24 hourly values of frequency weighted mean teriperature.

The array used to hold information on each of the observations in the DAYORA array which will be used to separate the counting process by any predetermined parameter.

The number of sets (i.e. seasons, months, cruises, etc.) of data to be analyzed.

Within each set of data, the number of zones in which counting will be performed to find the frequency of occurrence. 
TABLE 6 (Continued)

\begin{tabular}{ll}
\hline FORTRAN & DEFINITION \\
\hline $\mathrm{X}$ & $\begin{array}{l}\text { The starting value or the upper limit } \\
\text { of the highest value zone. }\end{array}$ \\
ZELTAX & $\begin{array}{l}\text { Zone increment; the increment between } \\
\text { each value contained in the zonE } \\
\text { array. }\end{array}$ \\
$\mathrm{N}$ & $\begin{array}{l}\text { Within each set of data being ana- } \\
\text { lyzed, the number of days of data } \\
\text { contained in the data cards. } \\
\text { KK }\end{array}$ \\
Counter used in the output to iden- \\
tify set of data number \\
Counter used to identify in the out- \\
put each of the subsets of data \\
within each set of KK.
\end{tabular}




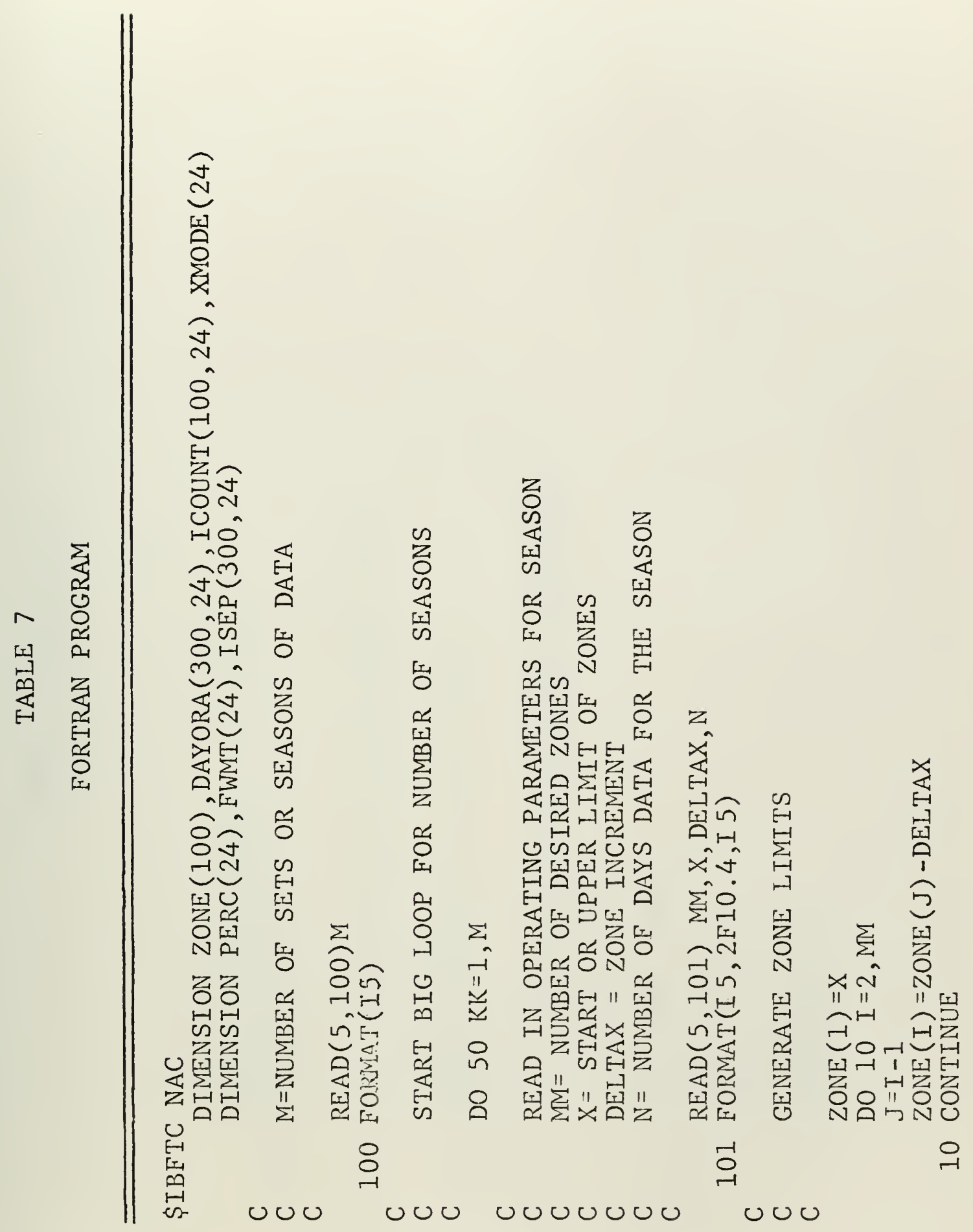




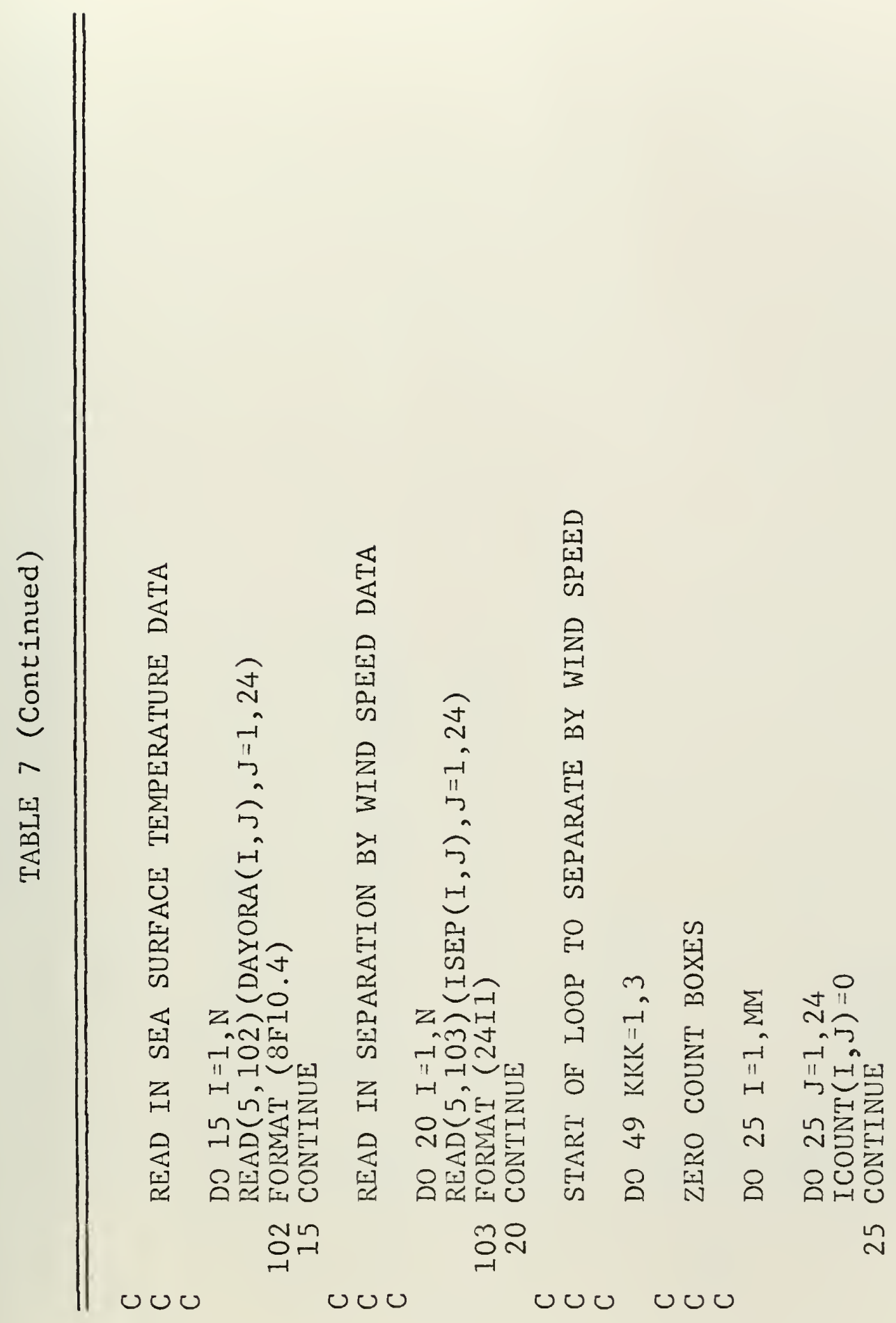




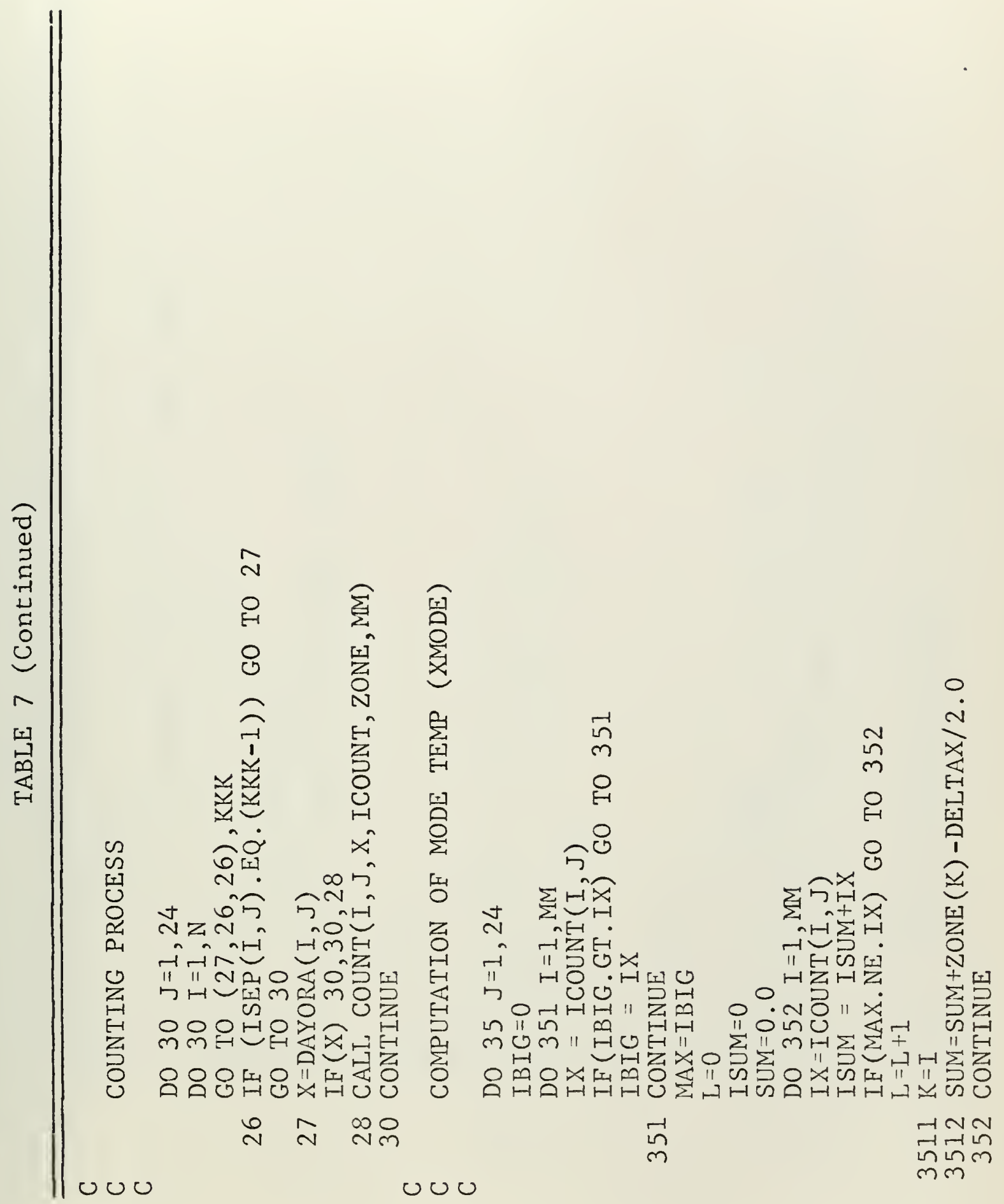




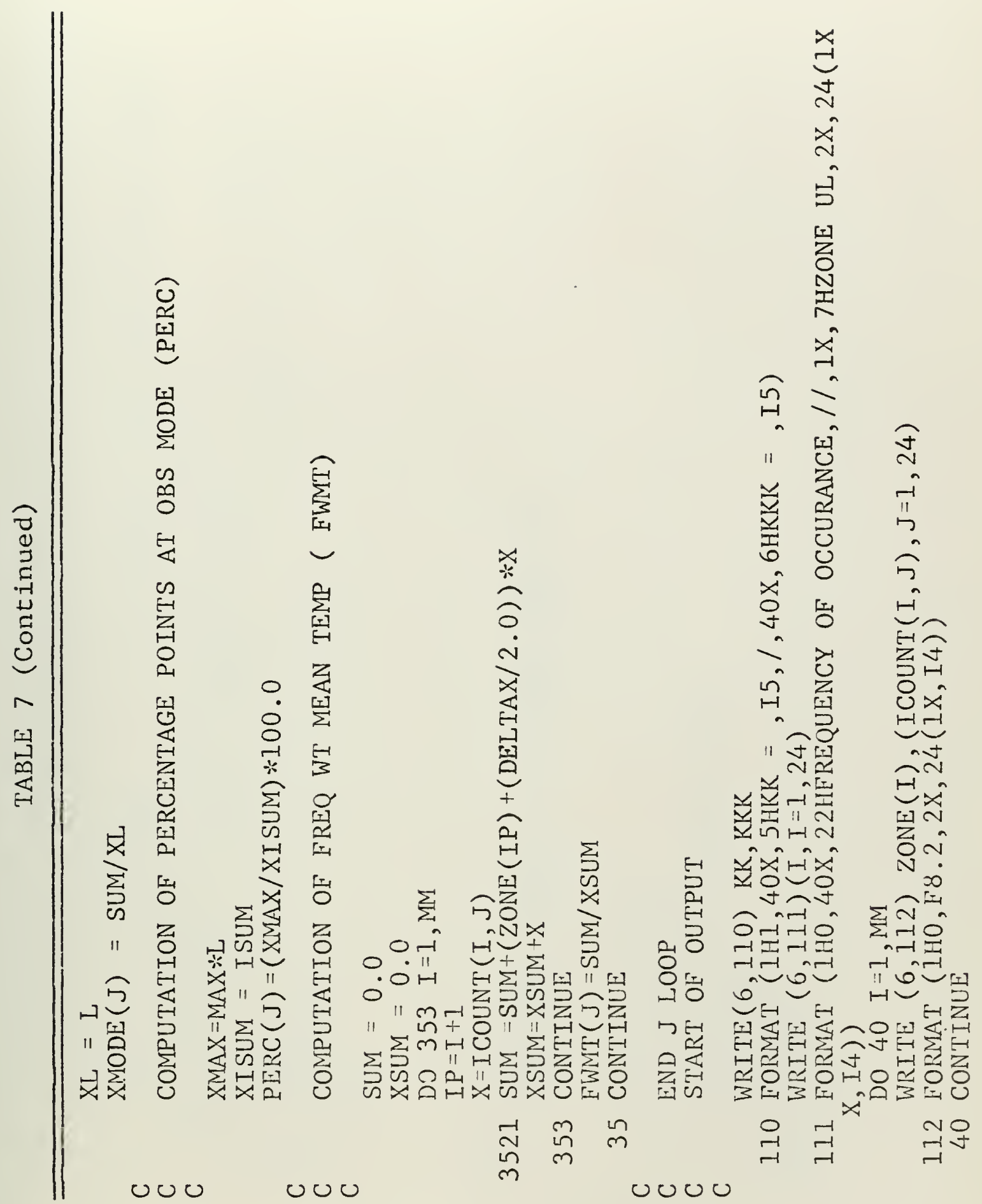



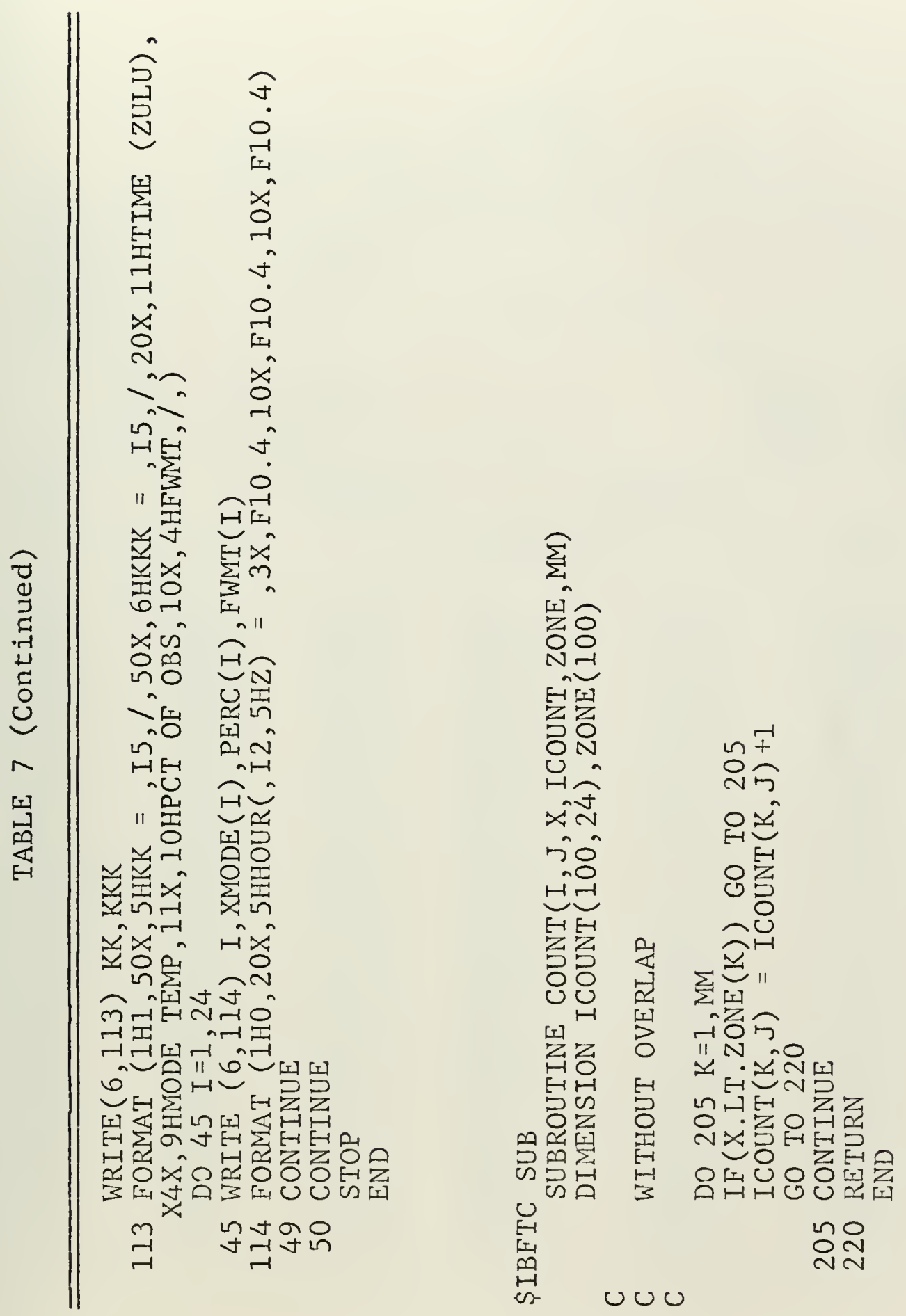
APPENDIX B

EXAMPLE DATA SUMRARY

TABLE 8

EXAMPLE DATA SHEET FOR CROSSING A-1

\begin{tabular}{|c|c|c|c|c|c|c|}
\hline \multicolumn{3}{|c|}{$\begin{array}{ll}\text { Season: } & \begin{array}{l}\text { Summer } \\
\text { Crossing No.: } \\
\text { A-1 } \\
\text { Cruise: }\end{array} \\
\text { Start: } & 66-\mathrm{A}-11 \\
\text { Lat: } & 22^{\circ} 29^{\prime} \mathrm{N} \\
\text { Long: } & 86^{\circ} 59^{\prime} \mathrm{W} \\
\text { Time: } & 080535 \mathrm{Z}\end{array}$} & \multicolumn{4}{|c|}{$\begin{array}{l}\text { August } 1966 \text { Stop: } \\
\text { Lat: } \\
\text { Long: } \\
\text { Time: }\end{array}$} \\
\hline $\begin{array}{l}\text { BT } \\
\text { No. }\end{array}$ & Time (Z) & $\begin{array}{c}\text { Distance } \\
\text { N.M. }\end{array}$ & $\mathrm{T}_{\mathrm{S}}$ & $\begin{array}{l}\text { Diurnal } \\
\text { Correction }\end{array}$ & $\mathrm{T}_{S}(\mathrm{c})$ & $\mathrm{T}_{100}$ \\
\hline $\begin{array}{l}44 \\
S-28 \\
45 \\
S-29 \\
46 \\
S-30 \\
47 \\
S-31 \\
48 \\
S-32 \\
49 \\
S-33 \\
50 \\
S-34 \\
51 \\
52 \\
53 \\
S-36 \\
55 \\
S-37 \\
56 \\
57\end{array}$ & $\begin{array}{r}080645 \\
0730 \\
0900 \\
0938 \\
1115 \\
1156 \\
1340 \\
1400 \\
1715 \\
1800 \\
1945 \\
2033 \\
2210 \\
2256 \\
090035 \\
0200 \\
0400 \\
0503 \\
0800 \\
0938 \\
1100 \\
1300\end{array}$ & $\begin{array}{r}11.0 \\
20.0 \\
31.0 \\
39.2 \\
48.9 \\
56.9 \\
70.1 \\
74.1 \\
96.1 \\
105.2 \\
113.0 \\
122.2 \\
132.0 \\
141.8 \\
151.8 \\
162.1 \\
177.1 \\
190.1 \\
205.3 \\
215.1 \\
223.6 \\
238.3\end{array}$ & $\begin{array}{l}28.5 \\
28.4 \\
28.5 \\
28.0 \\
28.4 \\
29.0 \\
29.5 \\
29.7 \\
29.9 \\
29.6 \\
29.8 \\
30.3 \\
29.9 \\
29.7 \\
29.6 \\
29.6 \\
29.5 \\
29.5 \\
29.5 \\
29.8 \\
30.0 \\
29.8\end{array}$ & $\begin{array}{l}+.14 \\
+.20 \\
+.34 \\
+.36 \\
+.38 \\
+.37 \\
+.31 \\
+.27 \\
-.02 \\
-.10 \\
-.26 \\
-.31 \\
-.37 \\
-.39 \\
-.31 \\
-.28 \\
-.10 \\
0.00 \\
+.25 \\
+.36 \\
+.39 \\
+.34\end{array}$ & $\begin{array}{l}28.64 \\
28.60 \\
28.59 \\
28.36 \\
28.78 \\
29.37 \\
29.81 \\
29.91 \\
29.88 \\
29.50 \\
29.54 \\
29.99 \\
29.53 \\
29.31 \\
29.29 \\
29.32 \\
29.40 \\
29.50 \\
29.75 \\
30.16 \\
30.39 \\
30.14\end{array}$ & $\begin{array}{l}15.50 \\
16.50 \\
19.50 \\
24.00 \\
25.00 \\
26.50 \\
26.25 \\
26.50 \\
26.75 \\
27.10 \\
26.50 \\
26.60 \\
26.40 \\
26.50 \\
26.00 \\
25.75 \\
23.40 \\
20.50 \\
19.75 \\
19.25 \\
19.25 \\
18.50\end{array}$ \\
\hline
\end{tabular}


APPENDIX C

\section{FIGURES}




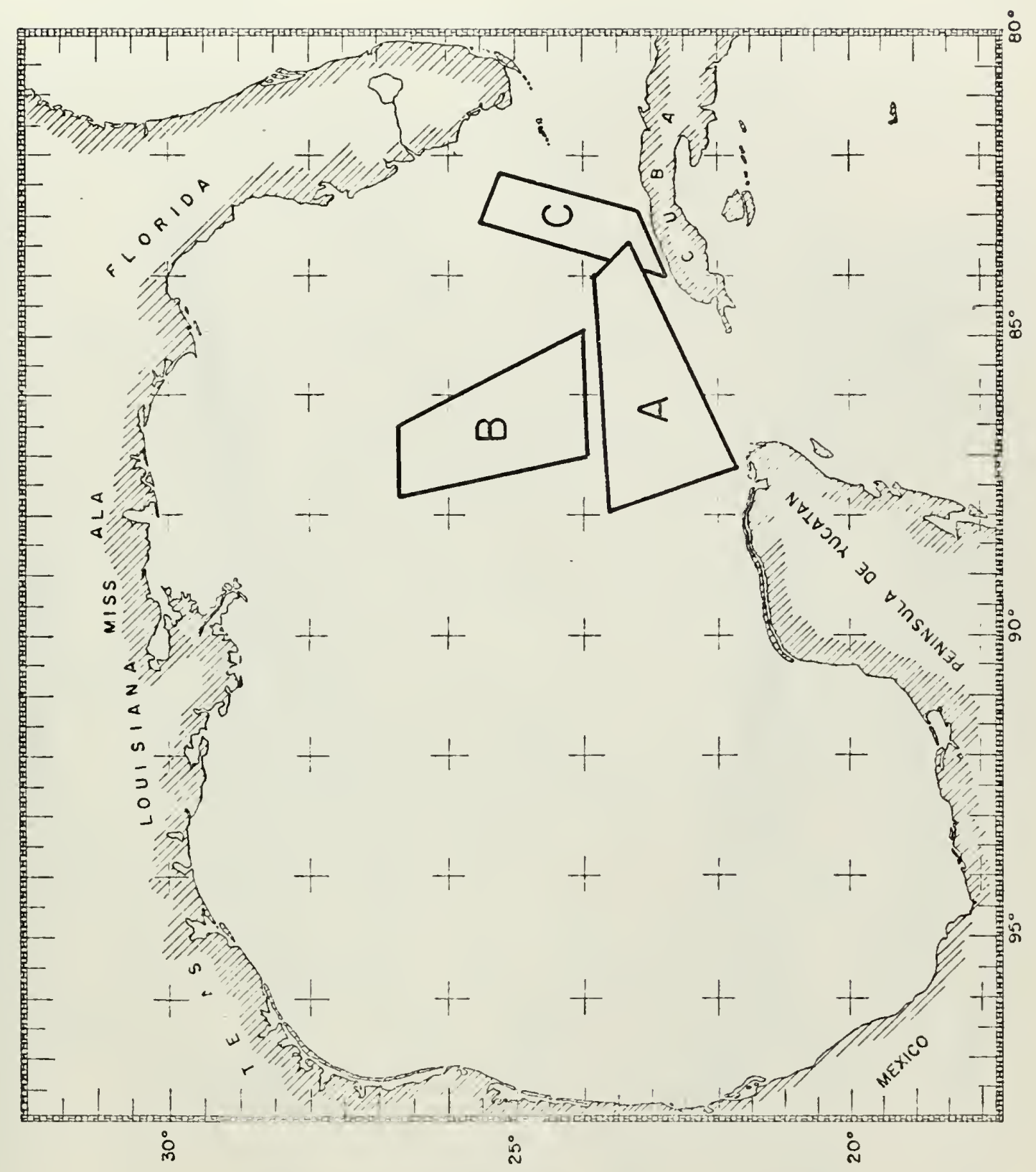

FIGURE ।

THREE AREAS INDICATING LOCATION OF CURRENT CROSS SECTIONS 
$22^{\circ} 29^{\prime}$ N. $86^{\circ} 59^{\prime} W$.

$25^{\circ} 03^{\prime} \mathrm{N} .83^{\circ} 56^{\prime} W$. $\downarrow$

HYDROCAST NO, $28 \quad 29 \quad 30 \quad 31$

$\begin{array}{llllllllllllll}\text { BT NO. } & 44 & 45 & 46 & 47 & 48 & 49 & 50 & 51 & 52 & 53 & 55 & 56 & 57\end{array}$

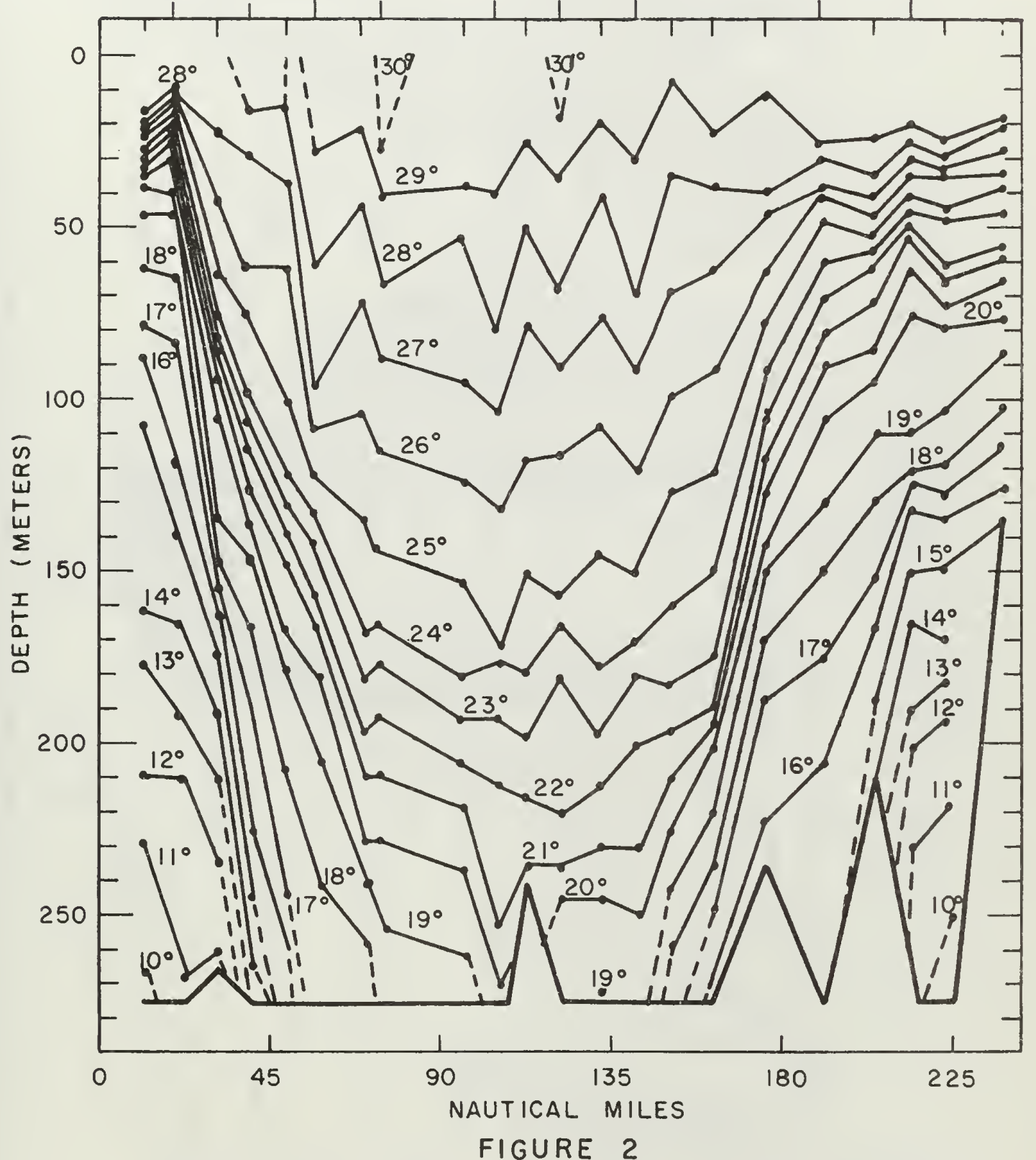

DEPTH OF ISOTHERMS ACROSS YUCATAN CURRENT CRUISE 66-A-11; AUGUST 1966 


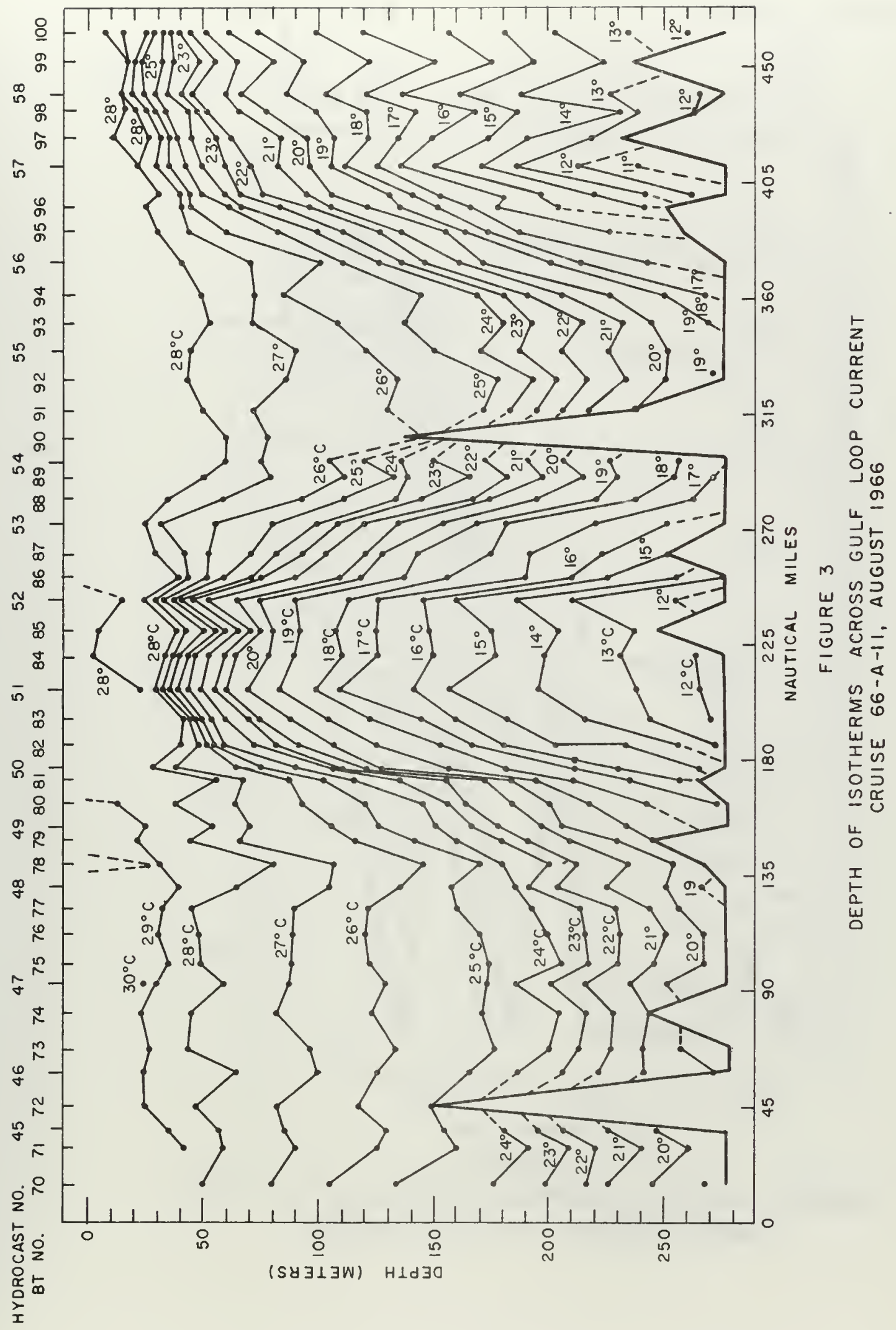



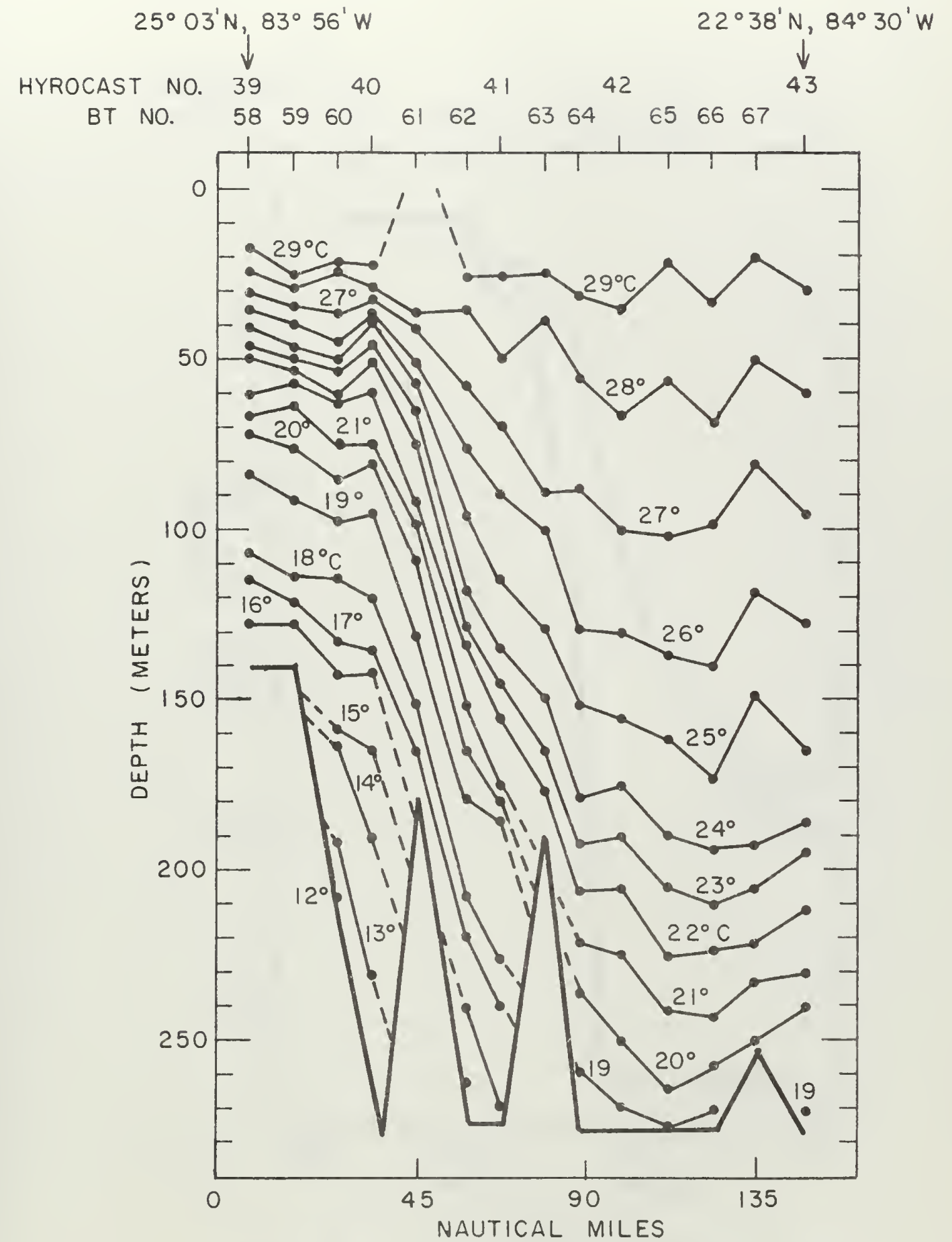

FIGURE 4

DEPTH OF ISOTHERMS ACROSS FLORIDA CURRENT CRUISE 66-A-11; AUGUST 1966 


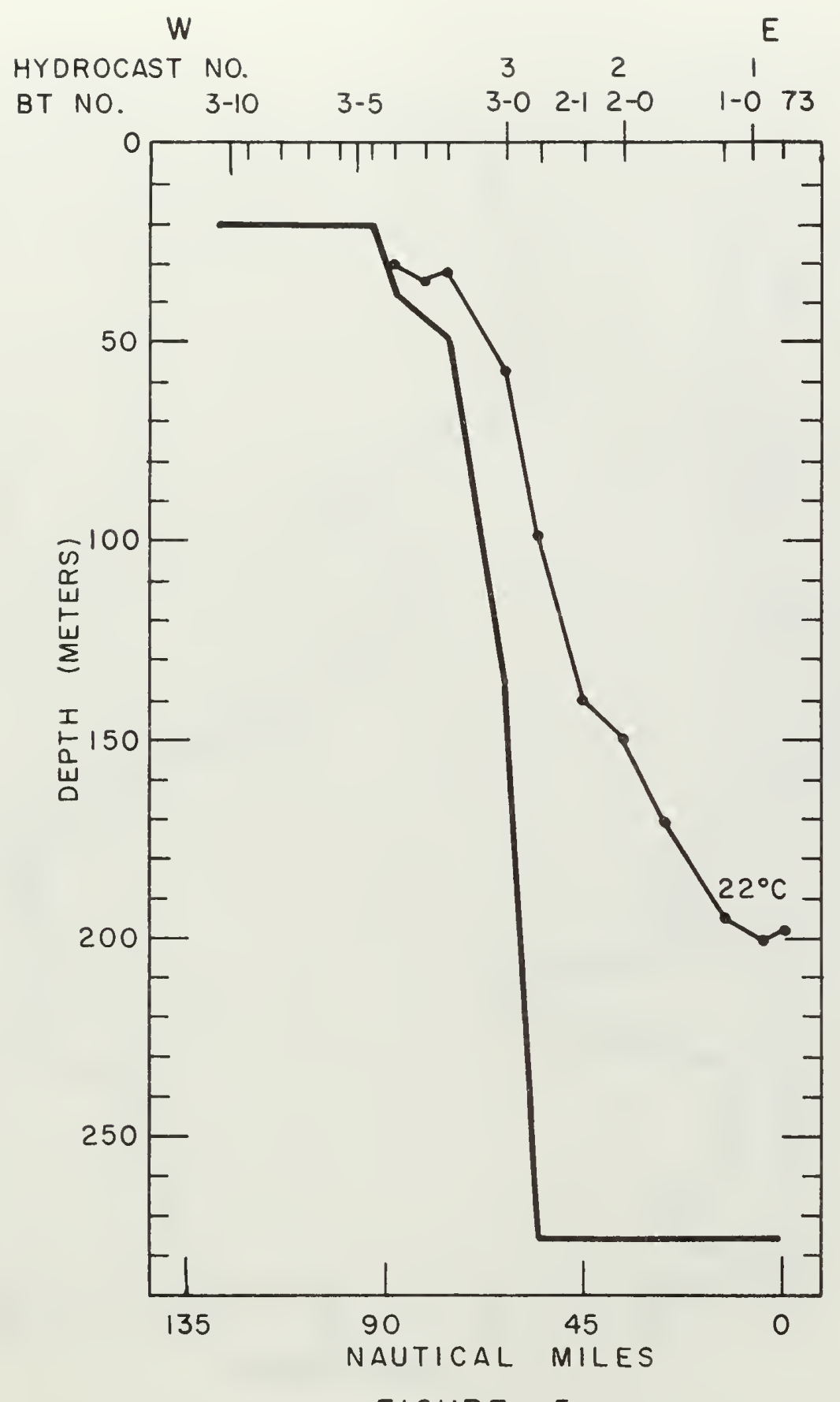

FIGURE 5

DEPTH OF $22^{\circ}$ ISOTHERM ACROSS THE YUCATAN CURRENT

CRUISE 65-A-16; NOVEMBER 1965 


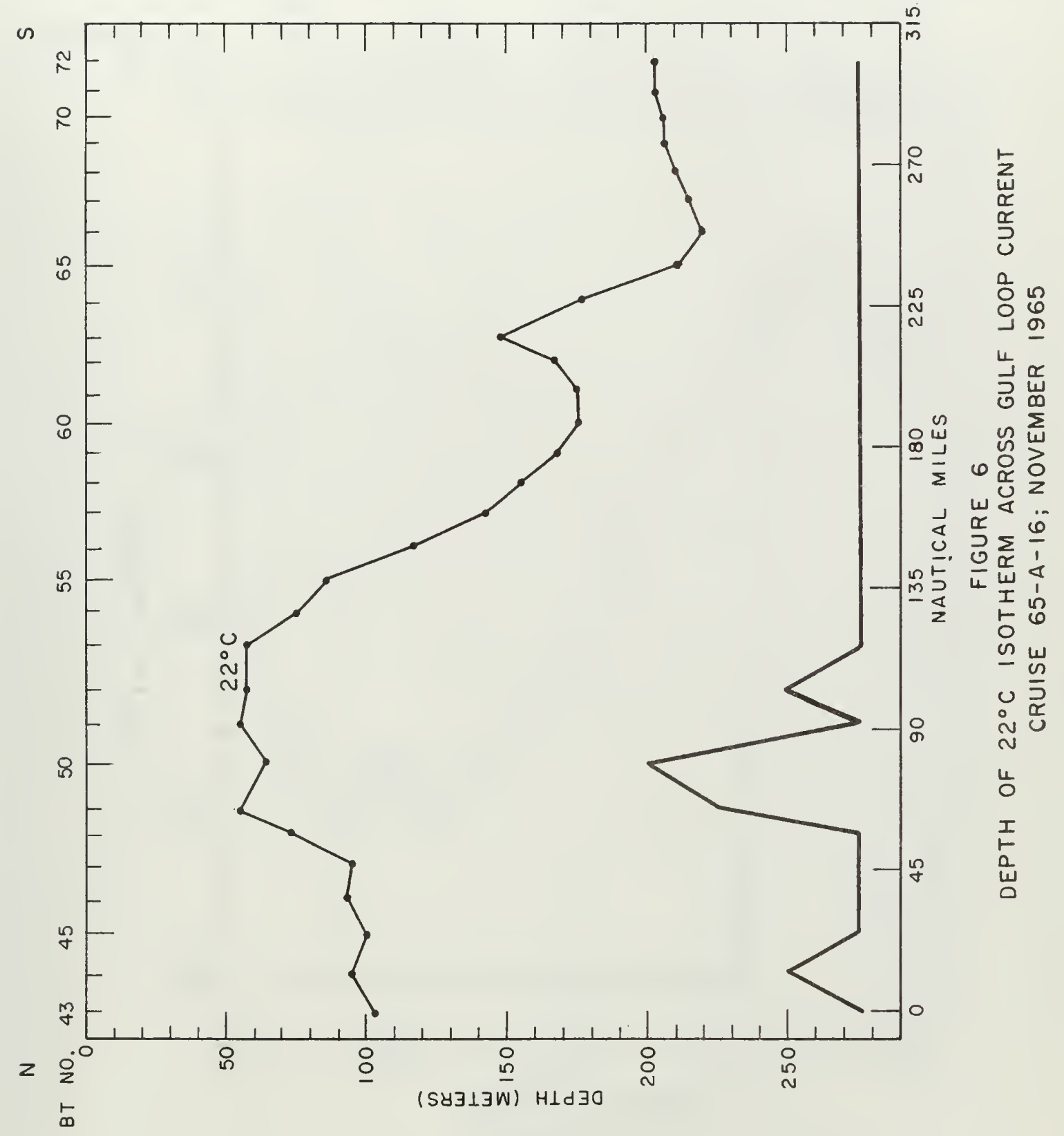




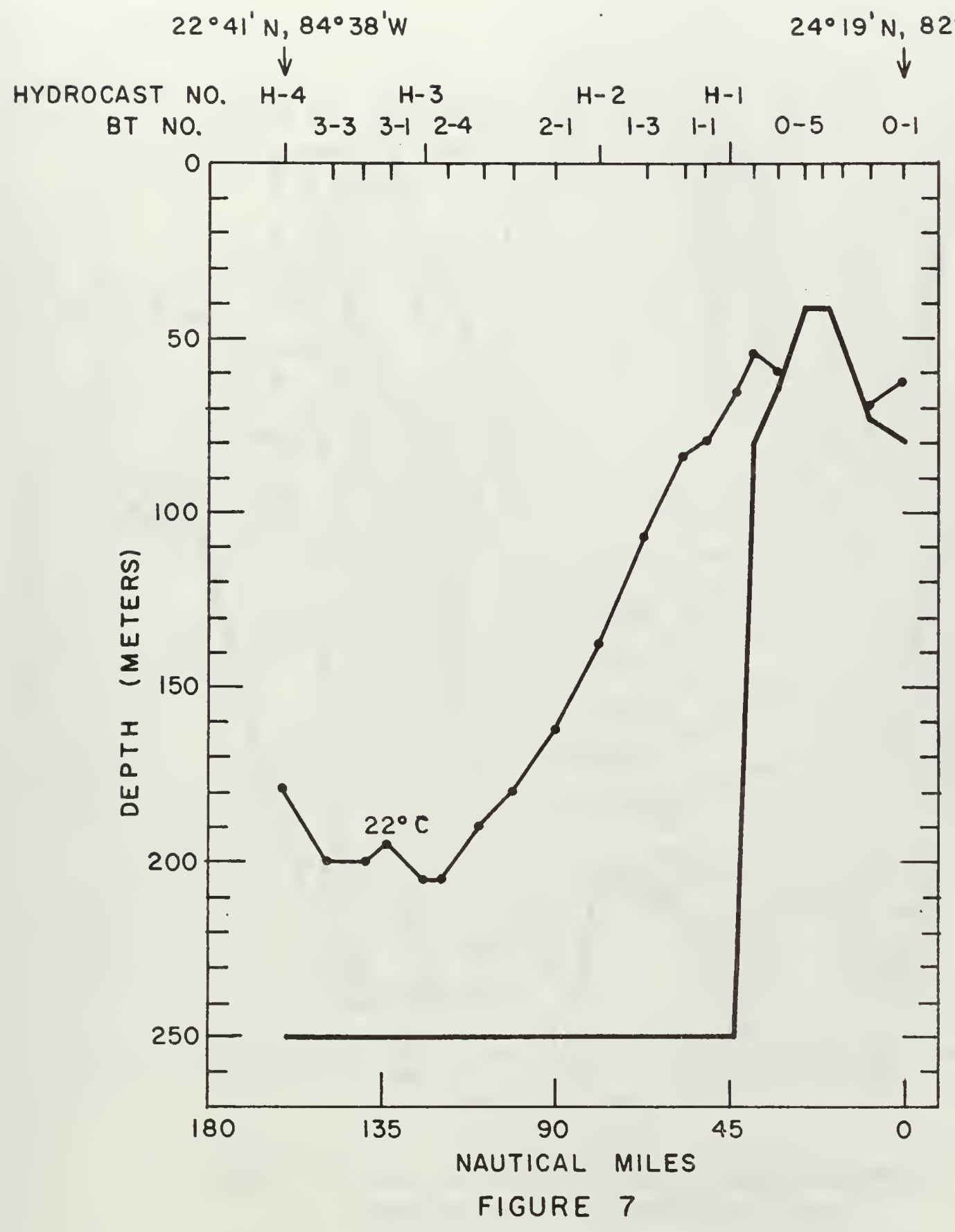

DEPTH OF $22^{\circ} \mathrm{C}$ ISOTHERM ACROSS FLORIDA CURRENT CRUISE 65-A-16; NOVEMBER 1966 


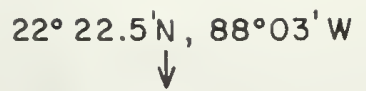

$24^{\circ} 47.5^{\prime} \mathrm{N}, 83^{\circ} 52^{\prime} W$
$\downarrow$ HYDROCAST NO. 16

BT NO. 75

78

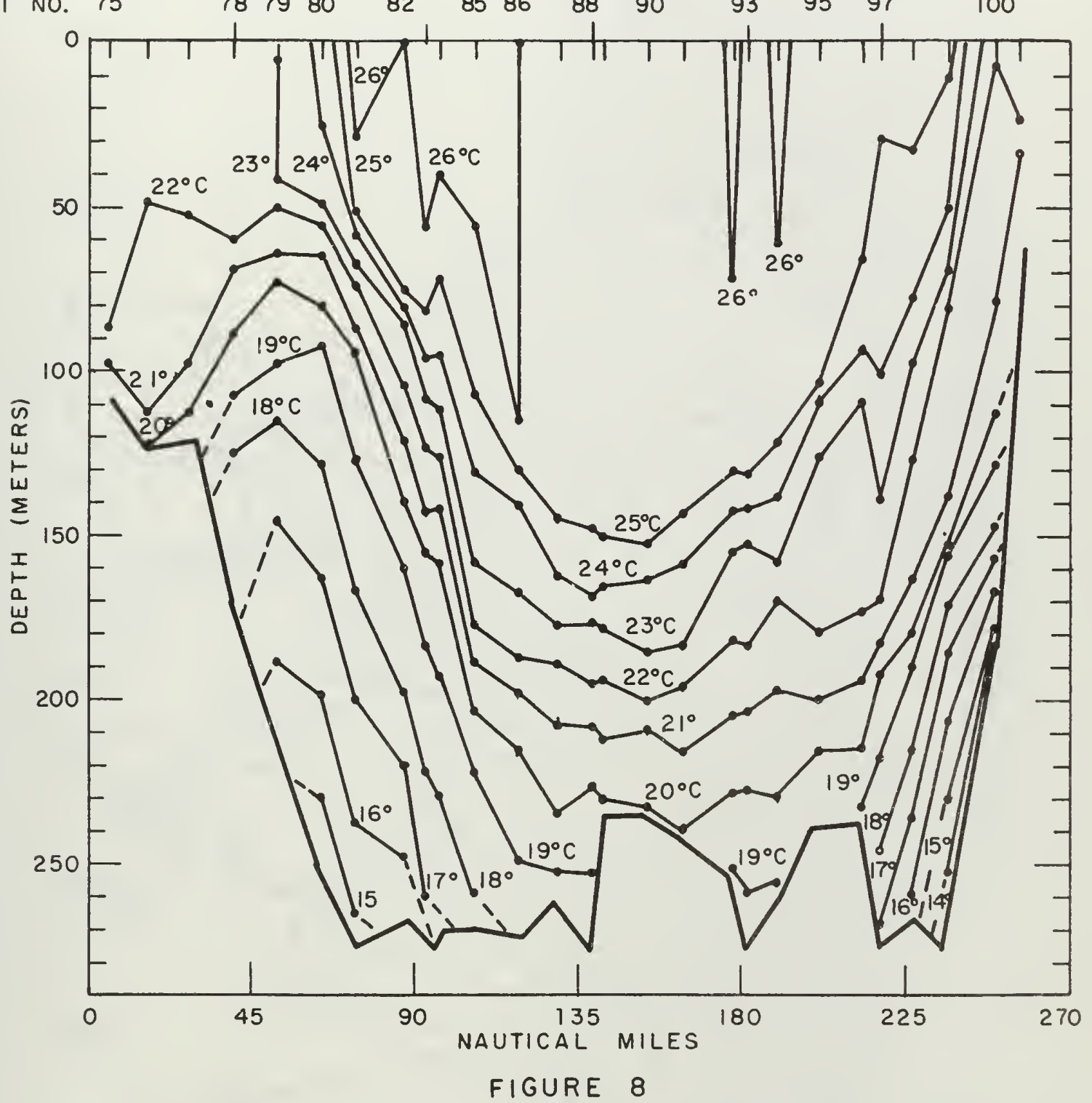

DEPTH OF ISOTHERMS ACROSS YUCATAN CURRENT CRUISE 66-A-3; FEBRUARY 1966 


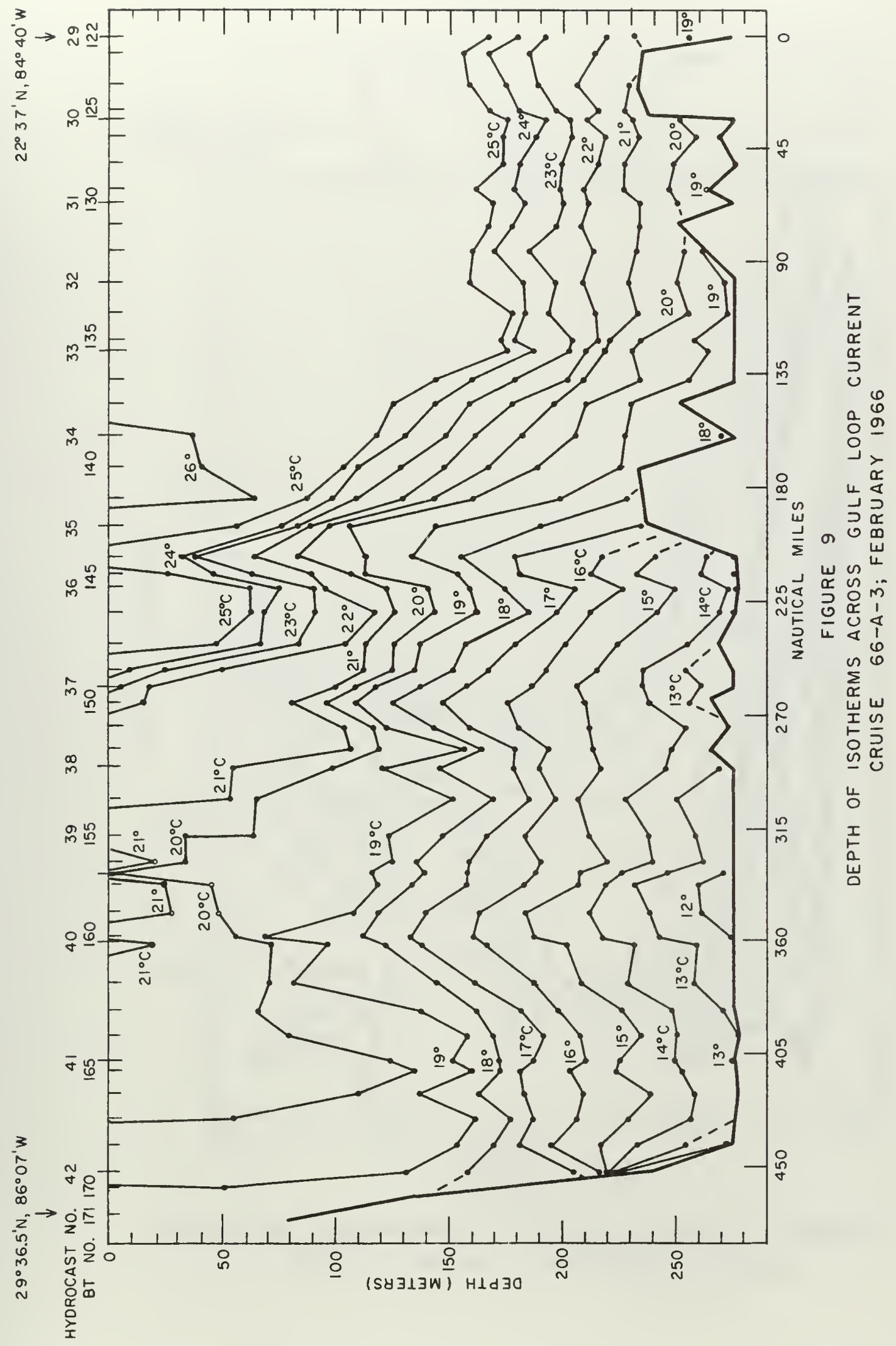




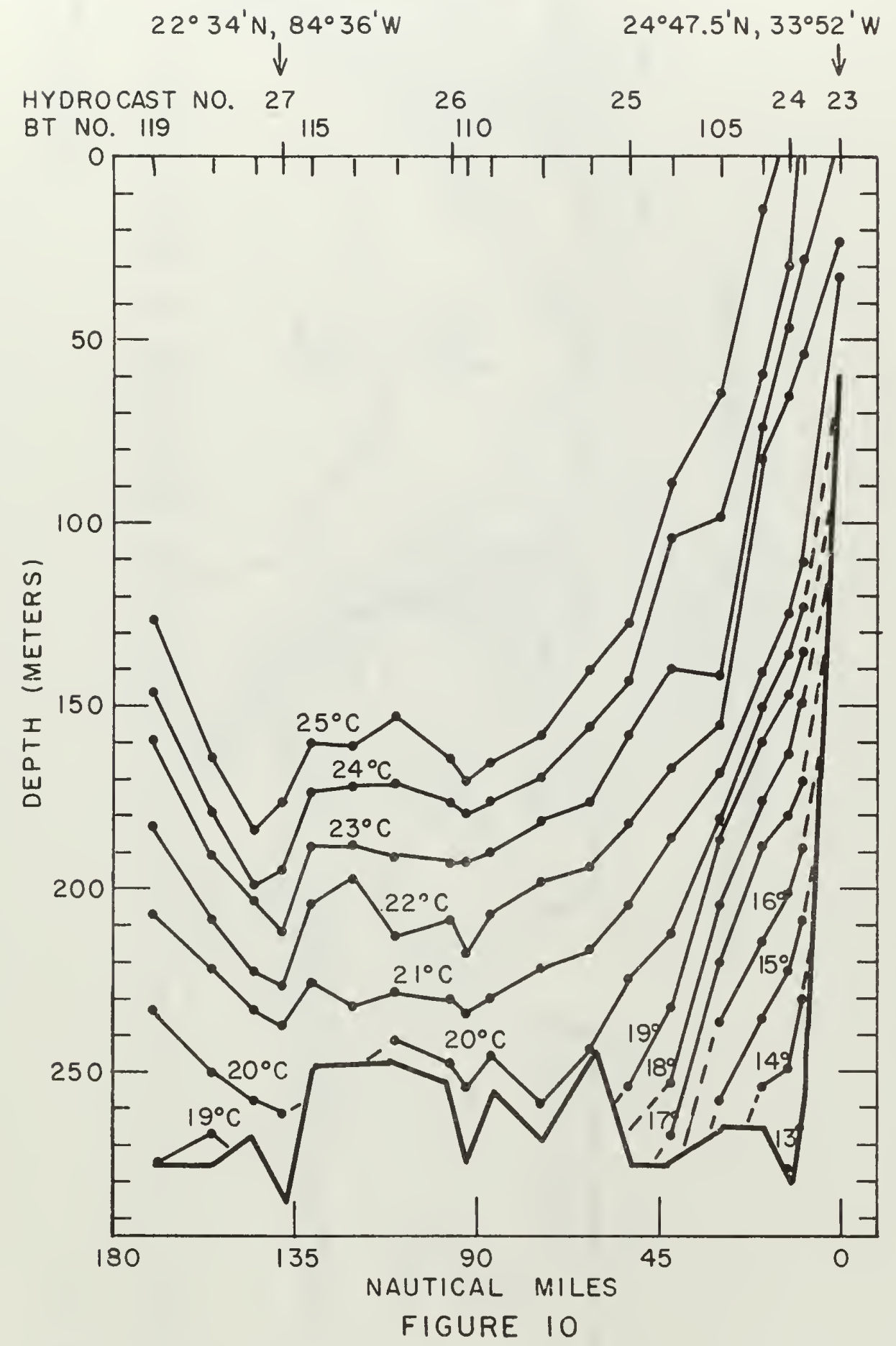

DEPTH OF ISOTHERMS ACROSS FLORIDA CURRENT CRUISE 66-A-3; FEBRUARY 1966 


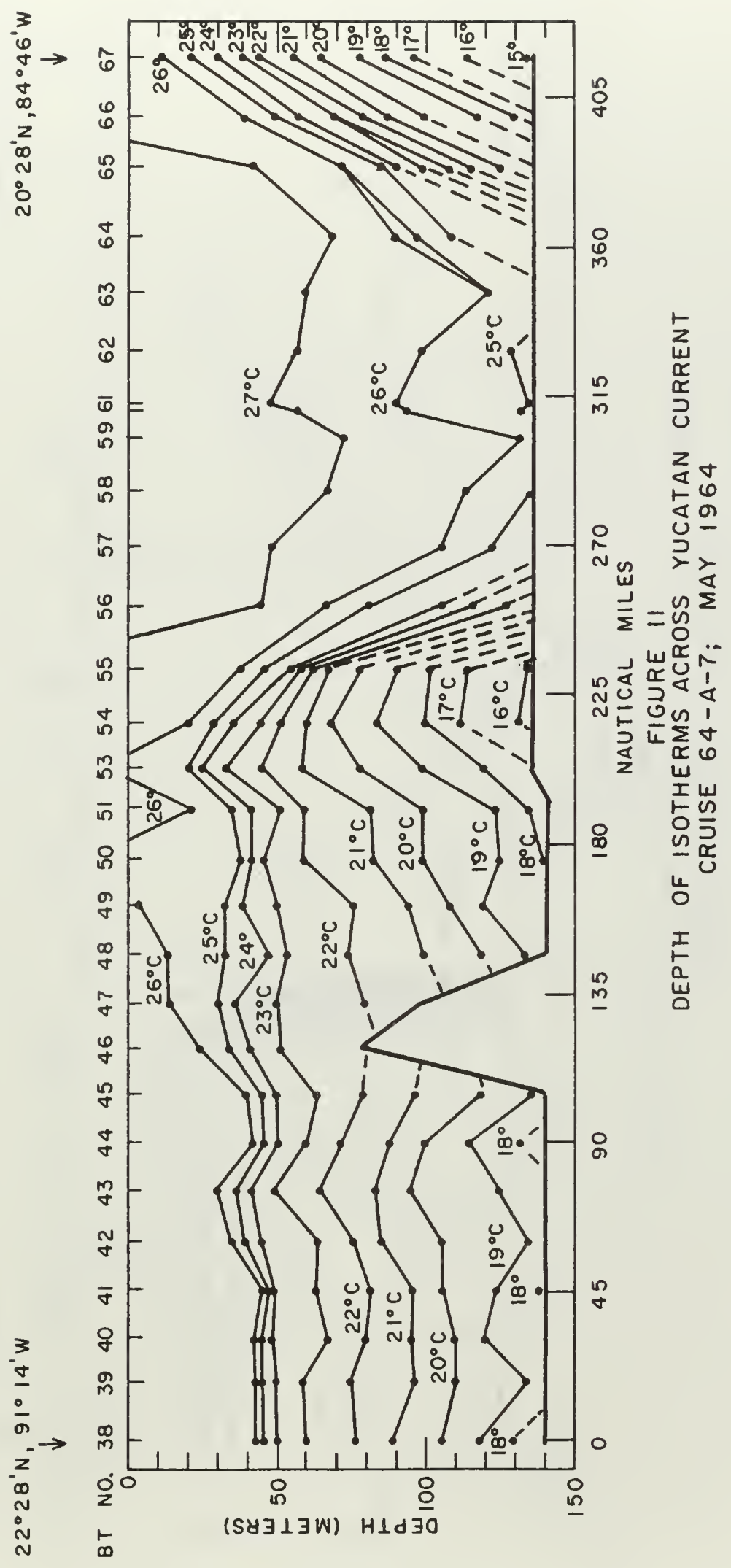




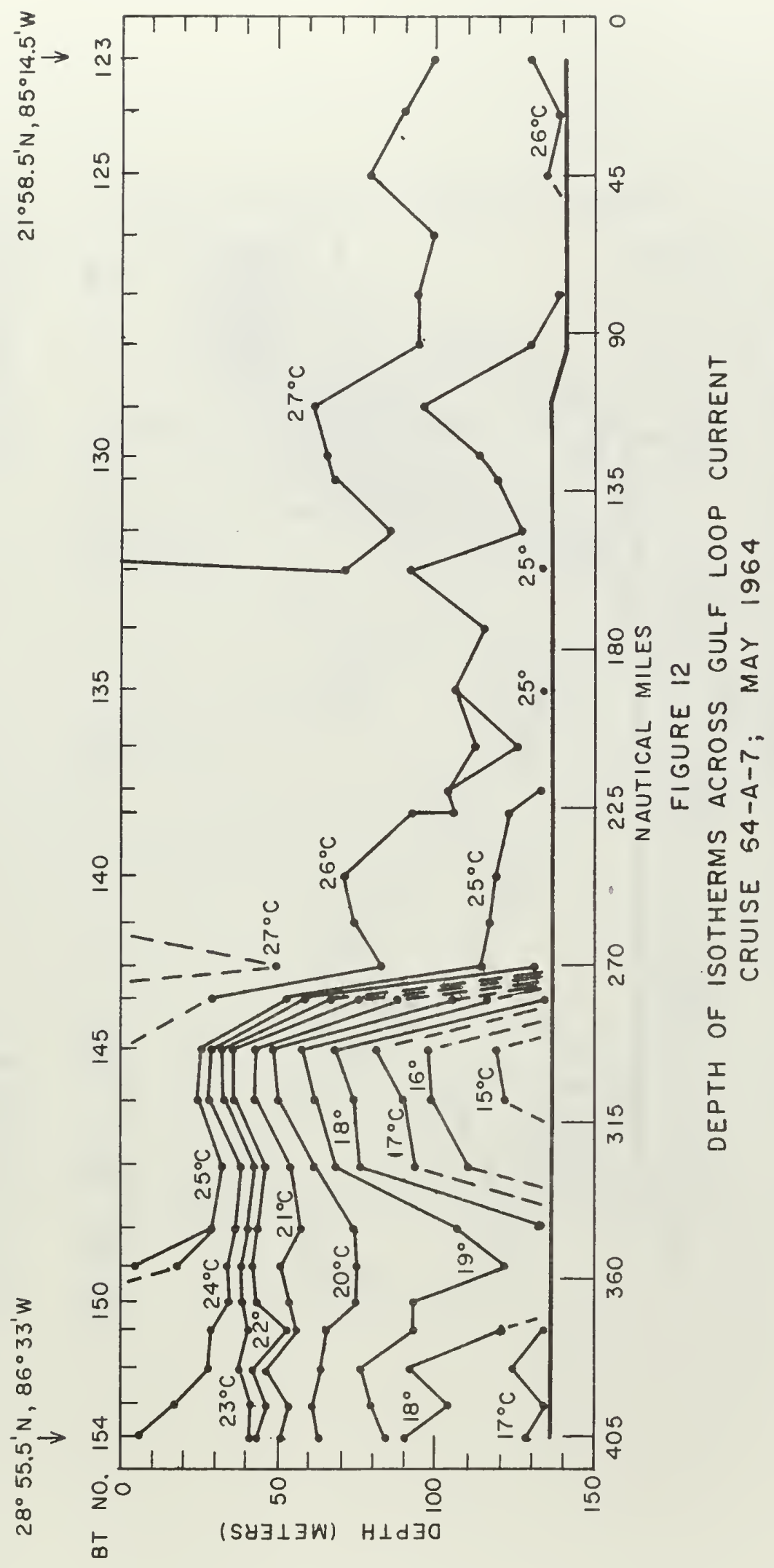





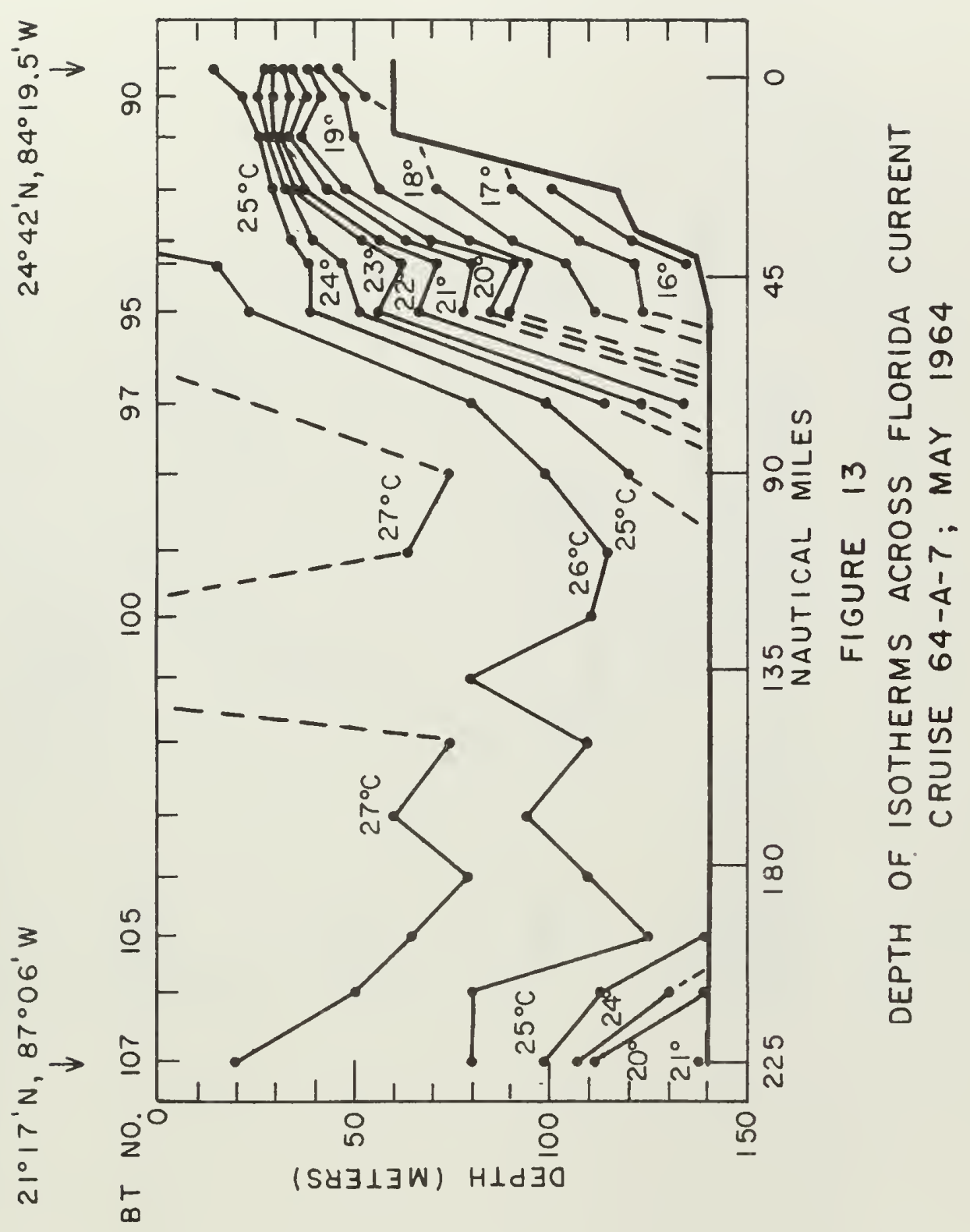




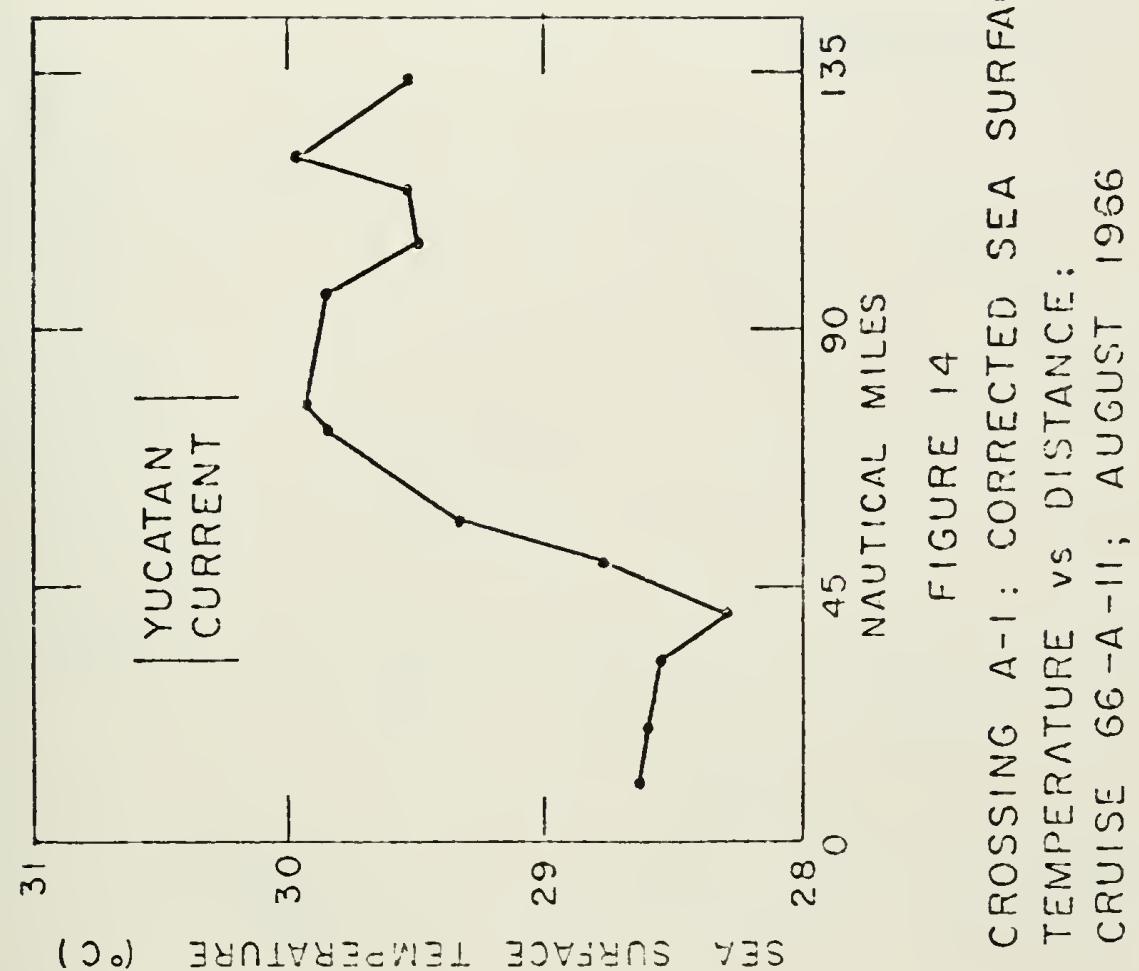





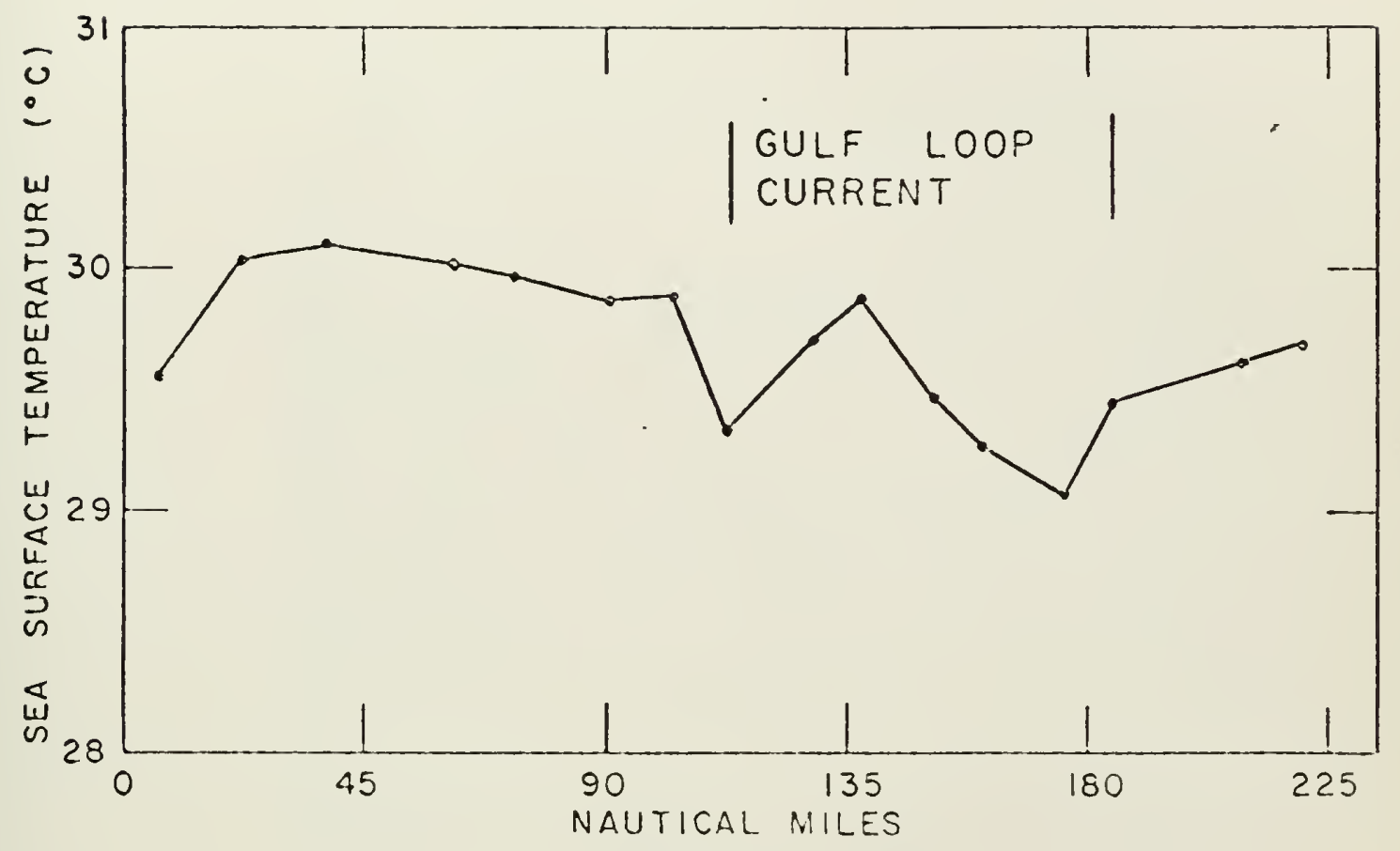

FIGURE 15

CROSSING B-1: CORRECTED SEA SURFACE TEMPERATURE VS DISTANCE: CRUISE 66-A-1I; AUGUST 1966 


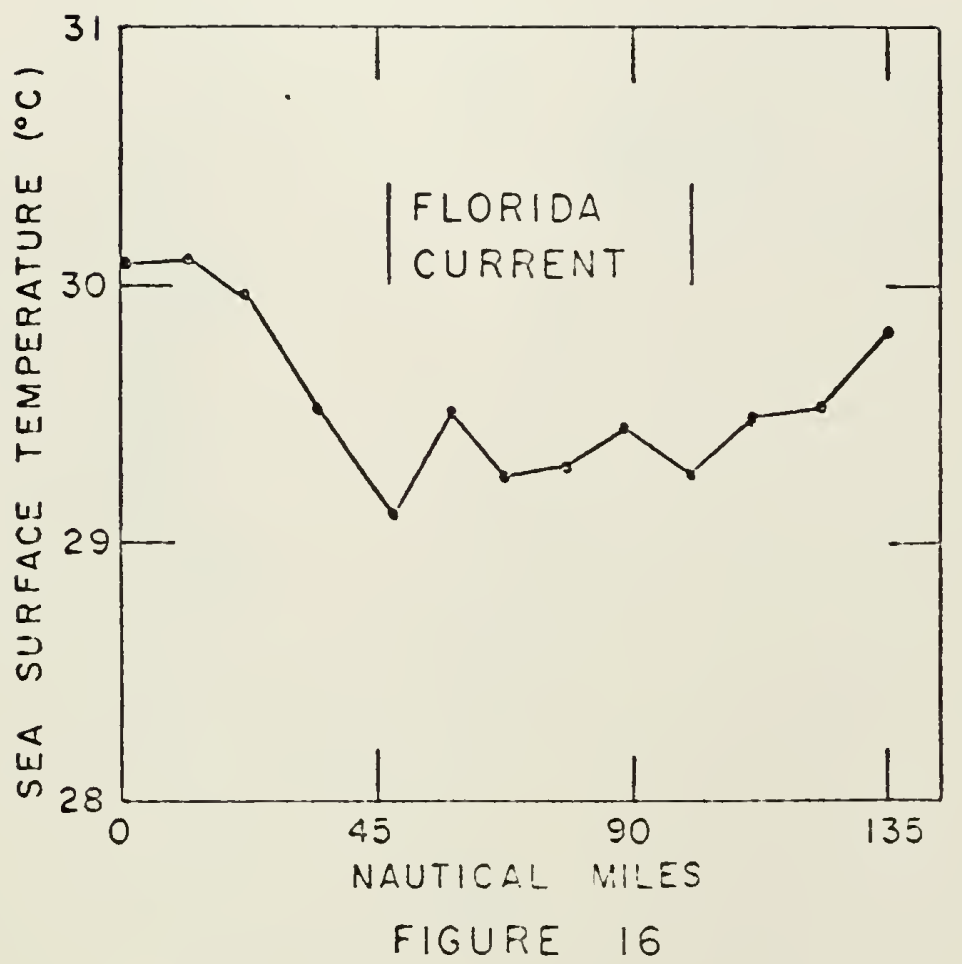

CROSSING C-1: CORRECTED SEA SURFACE TEHPERATURE VS DISTANCE: CRUISE 66-A-11; $A$ UUUST 1956 


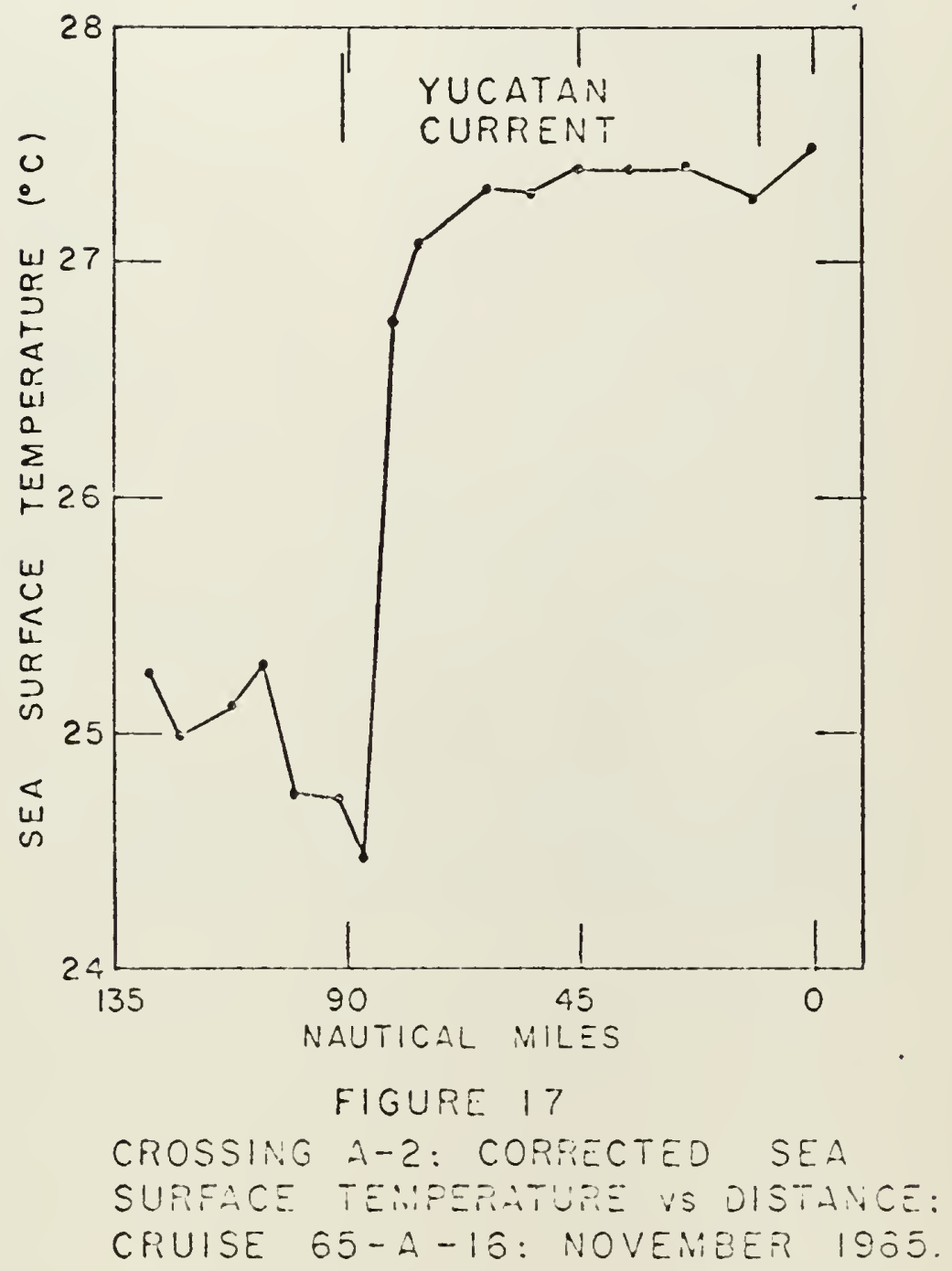


69

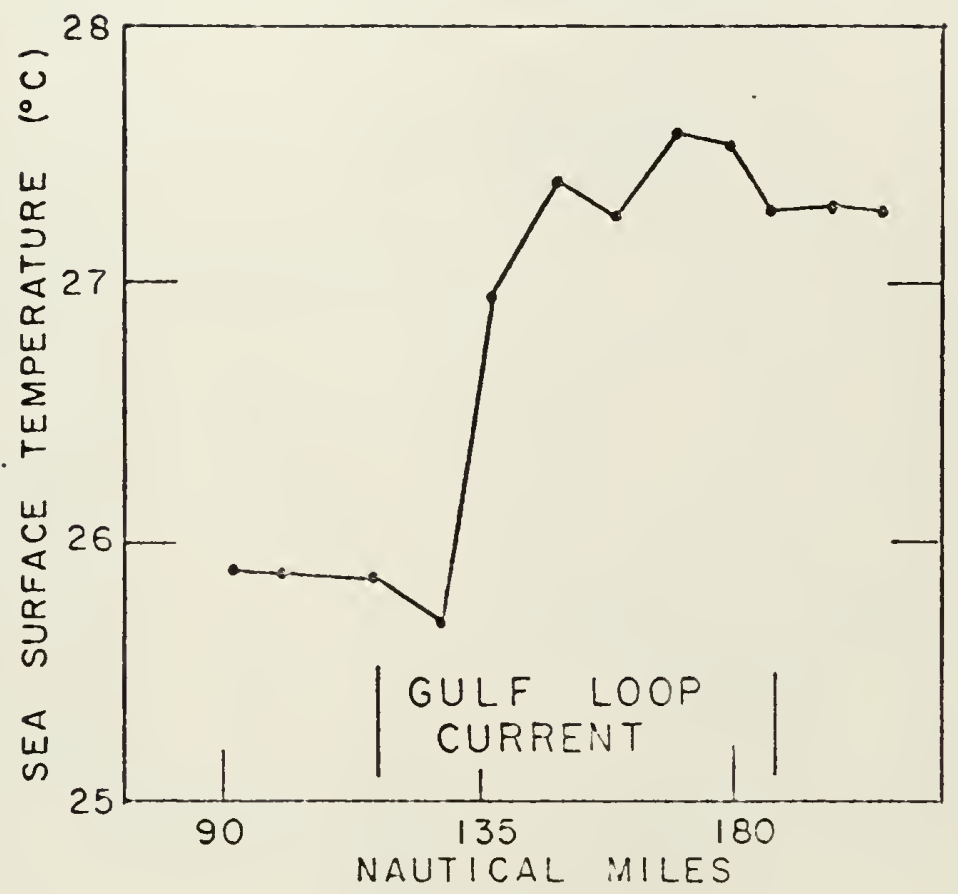

FIGURE 18

CROSSING B-2; CORRECTED SEA SURFACE TEMPERATURE VS DISTANCE: CRUISE 65-A-16; NOVEMBER. 


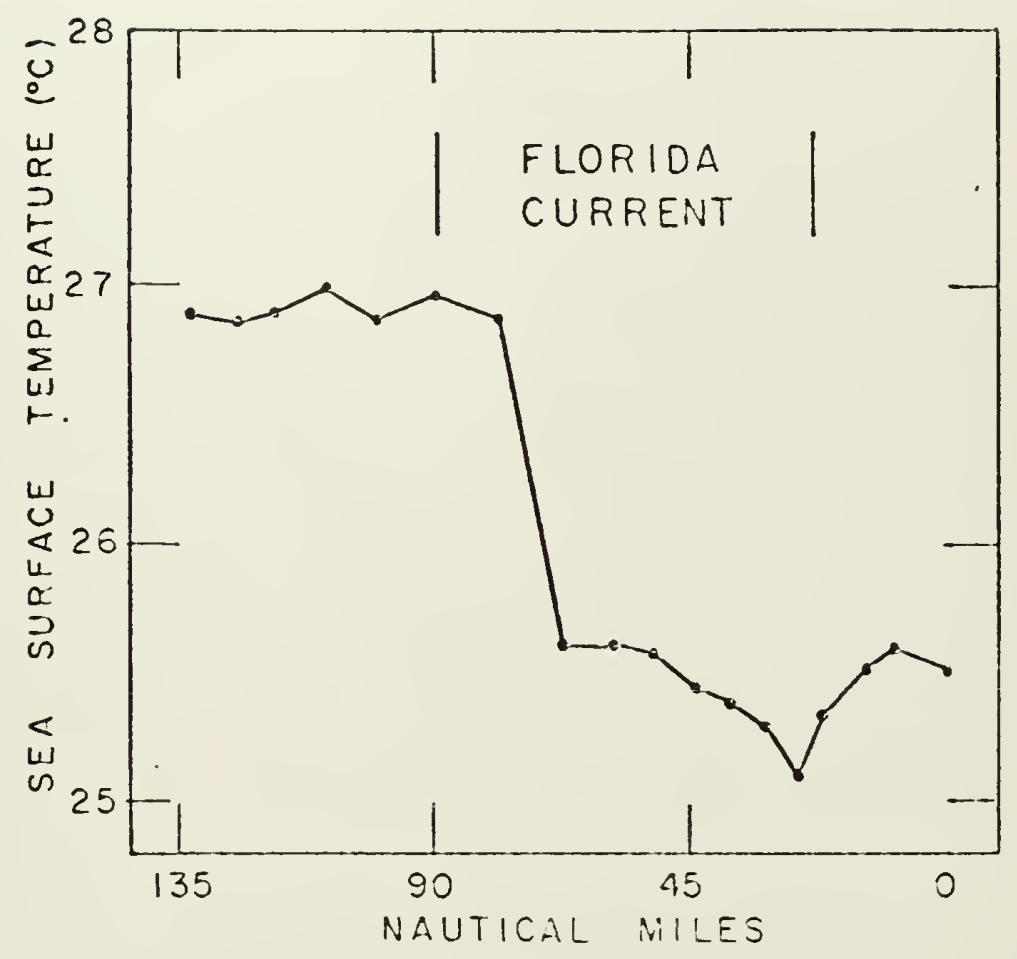

FIGURE 19

CROSSING C-2: CORRECTED SEA SURFACE TEMPERATURE VS DISTANCE: CRUISE 65-A-16; NOVEMEER 1960. 


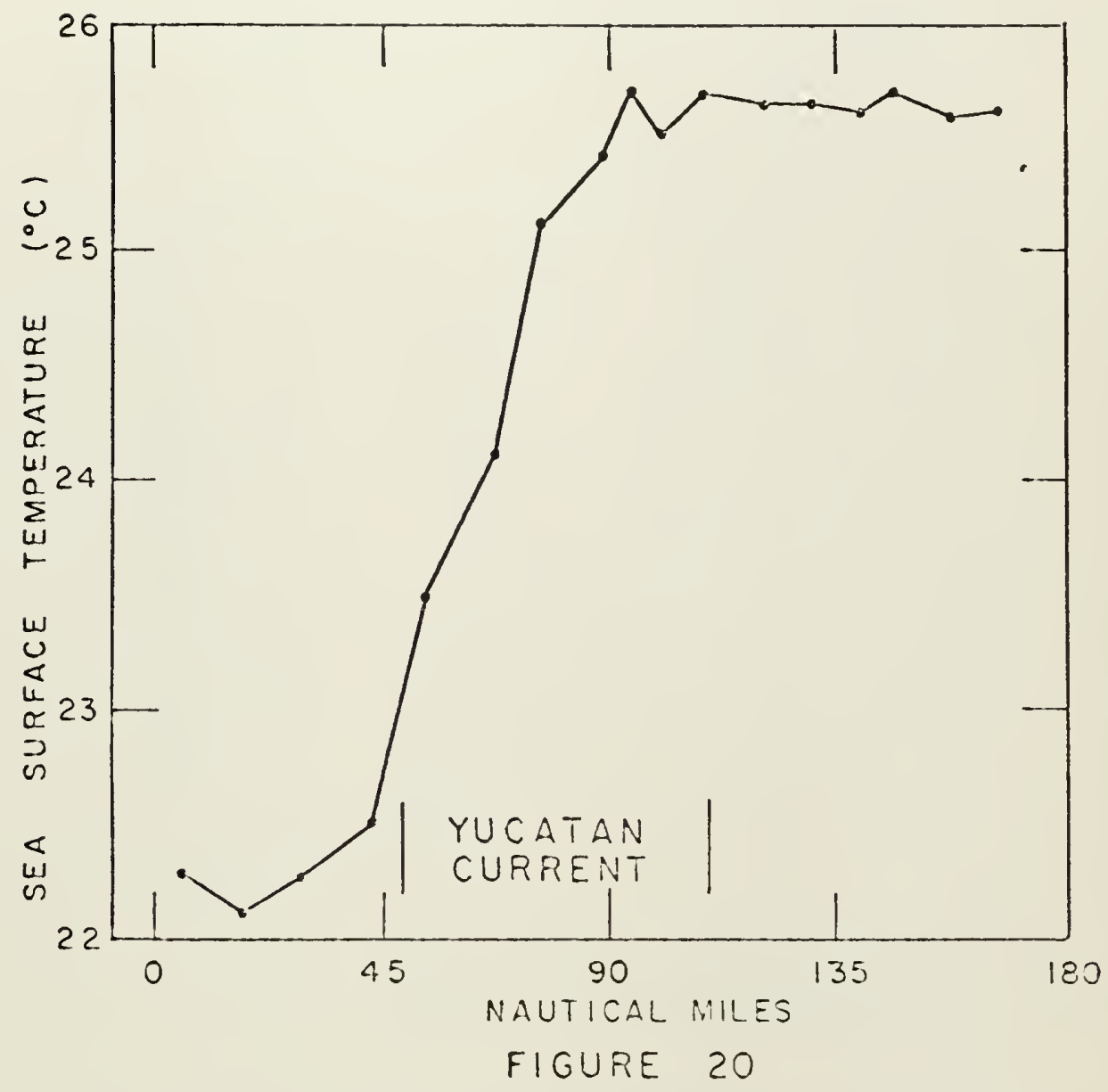

CROSSING A-3: CORRECTED SEA SURFACE TEMPERATURE VS OISTANCE: CRUISE 65-A-3: FEBRUARY 1966. 


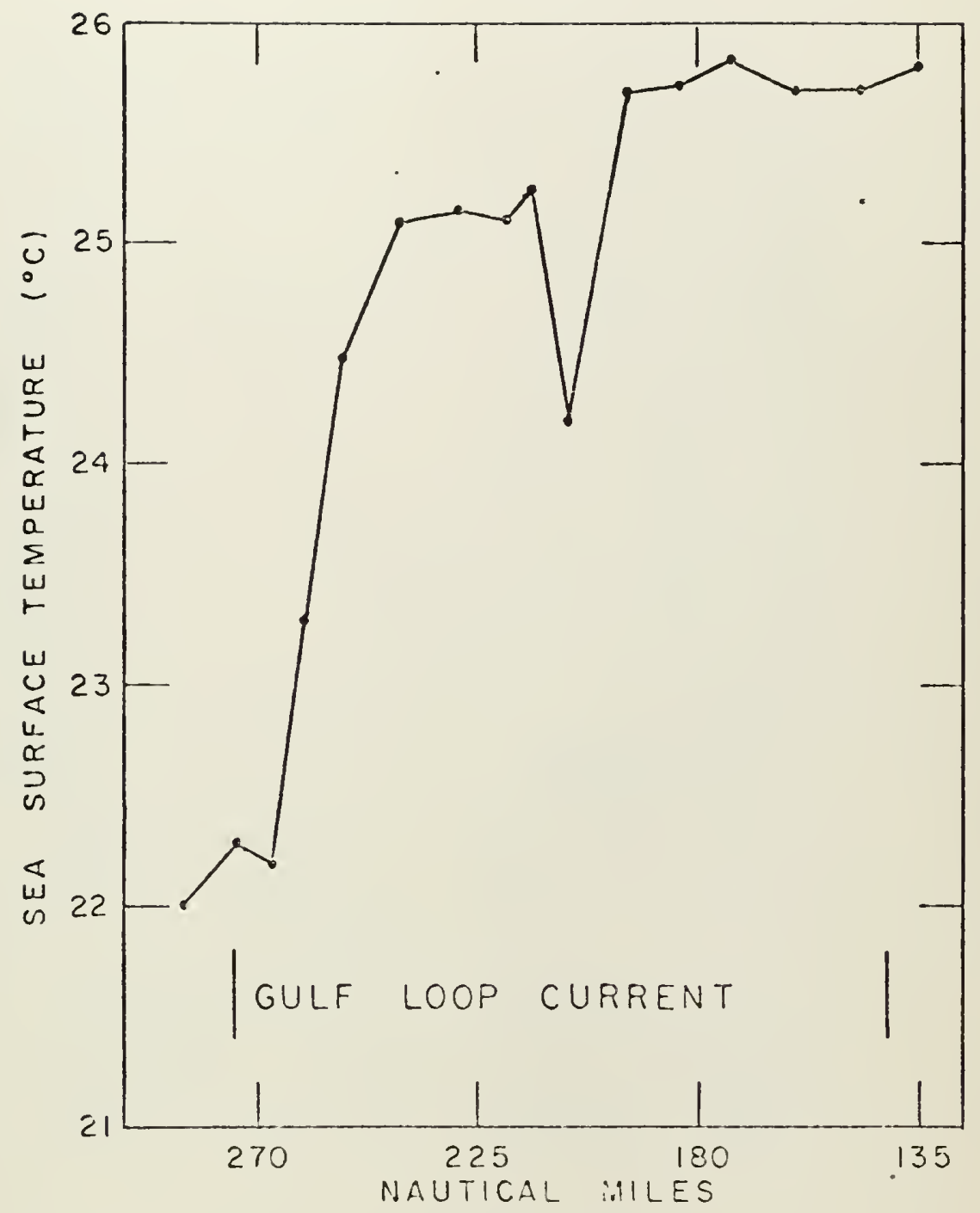

FIGURE 21

CROSSING B-3: CORRECTED SEA SURFACE TEMPERATURE VS DISTANCE: CRUISE 66-A-3; FEBRUARY 1966. 


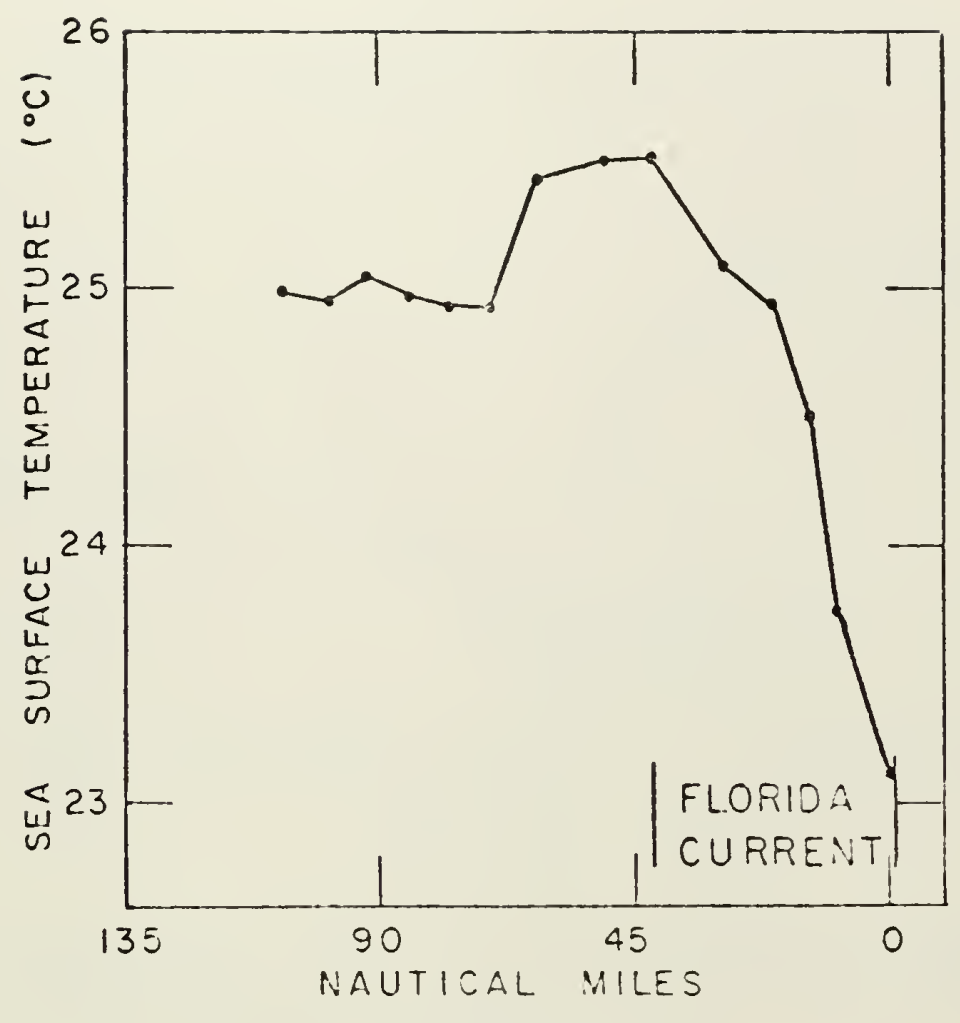

FIGURE 22

CROSSING C-3: CORRECTED SEA SURFACE TEMPERATURE VS OISTANCE CRUISE 66-A-16; FEBRUARY 1966 
74

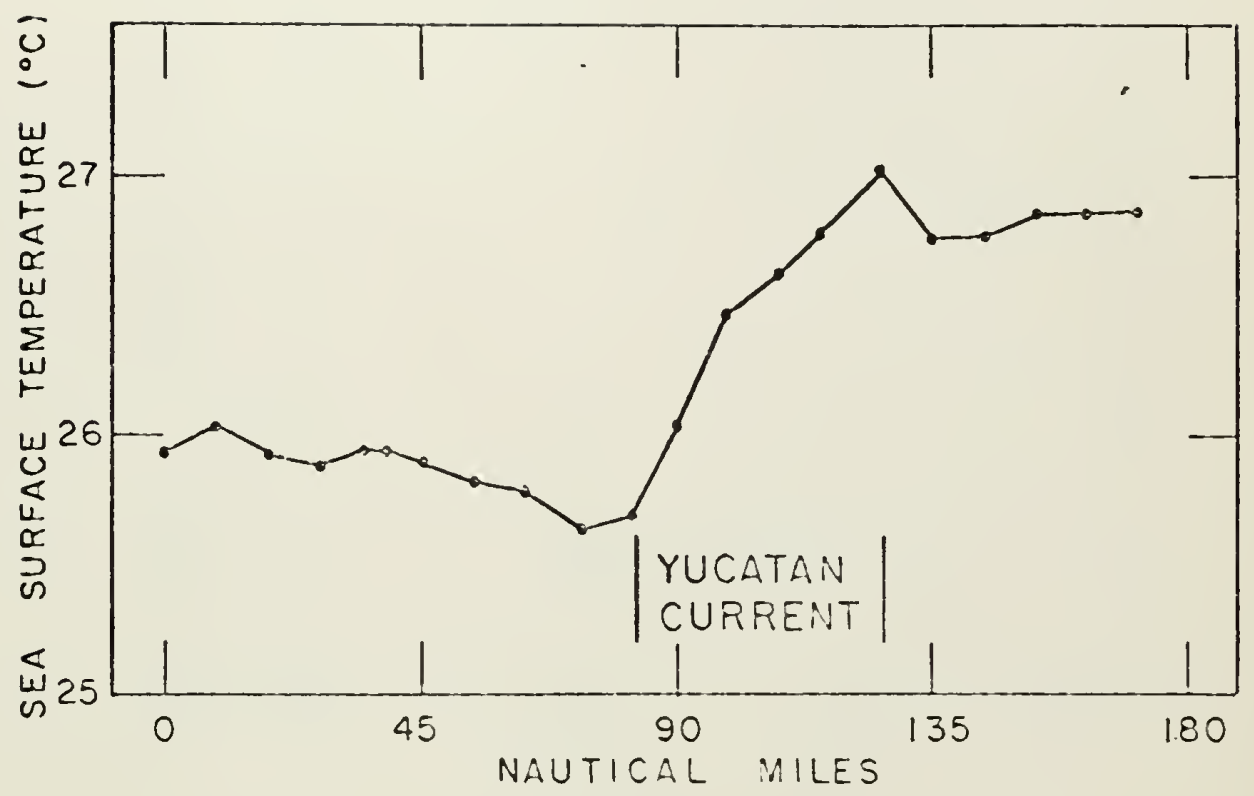

$$
\text { FIGURE } 23
$$

CROSSING A-4: CORRECTED SEA SURFACE TEMPERATURE VS DISTANCE: CRUISE 64-A-7; MAY 1968. 


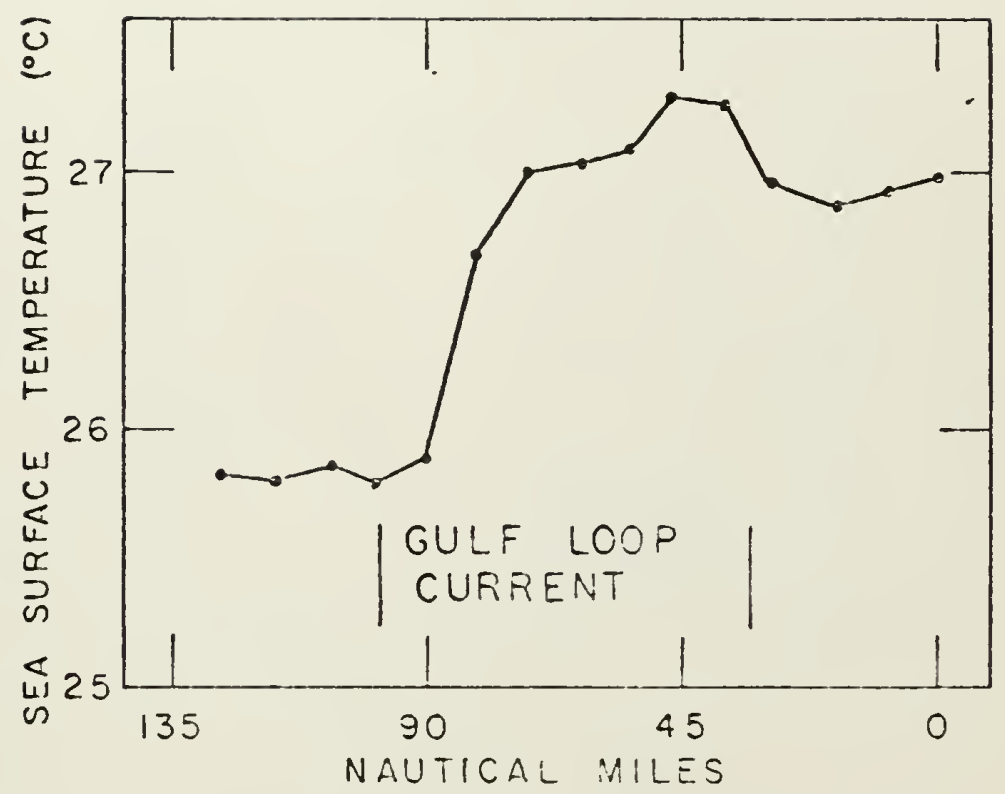

FIGURE 24

CROSSING B-4: CORRECTED SEA SURFACE TEMPERATURE US DISTANCE: CRUISE 64-A-7; NAY 1964 


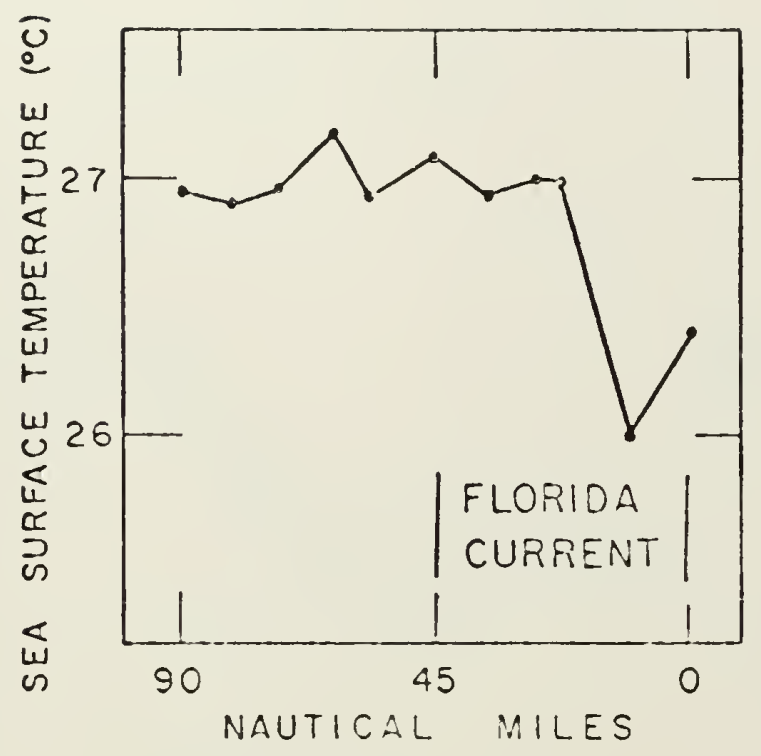

FIGURE 25

CROSSING C-4: CORRECTED SEA SURFACE TEMPEPATURE VS DISTANCE:

CRUISE 64-A-7; MAY 1964 

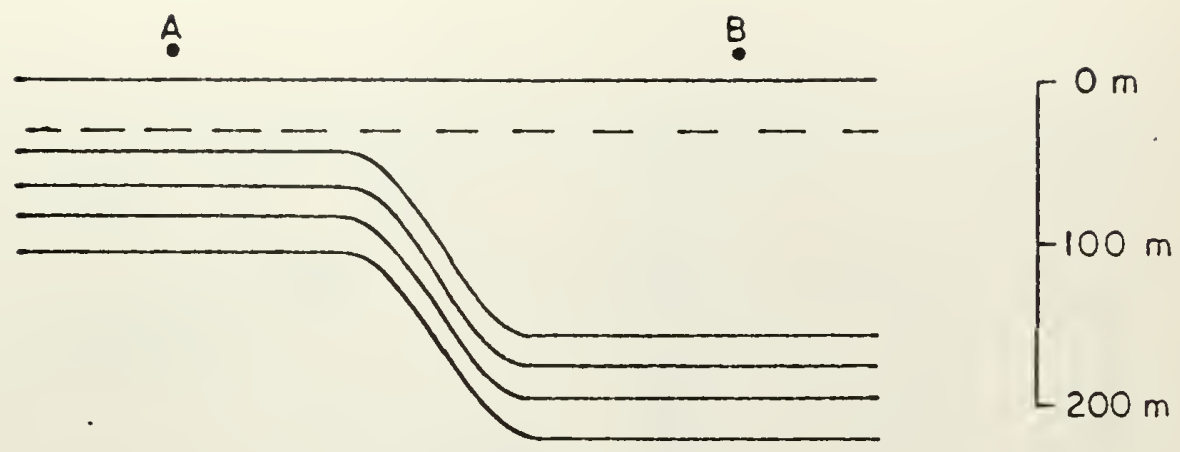

FIGURE $26(A)$
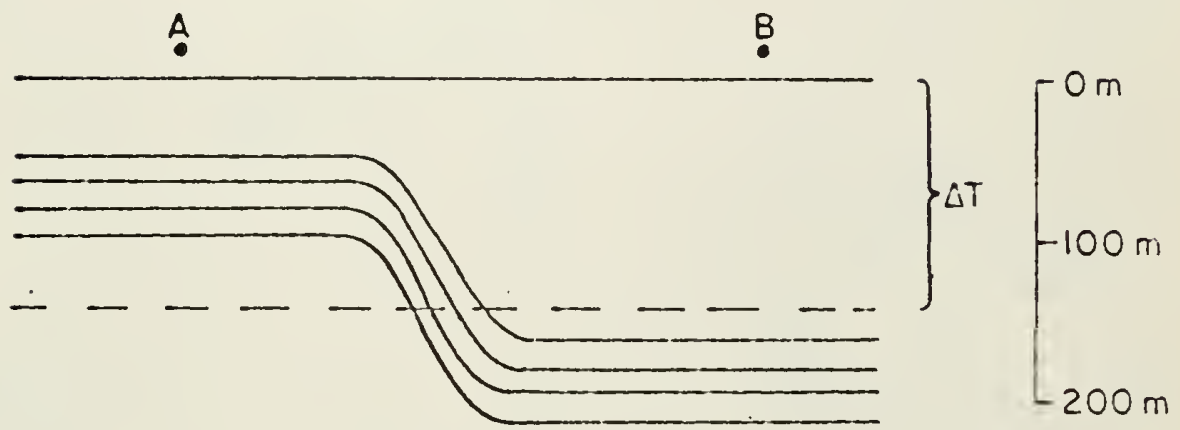

FIGURE $26(B)$
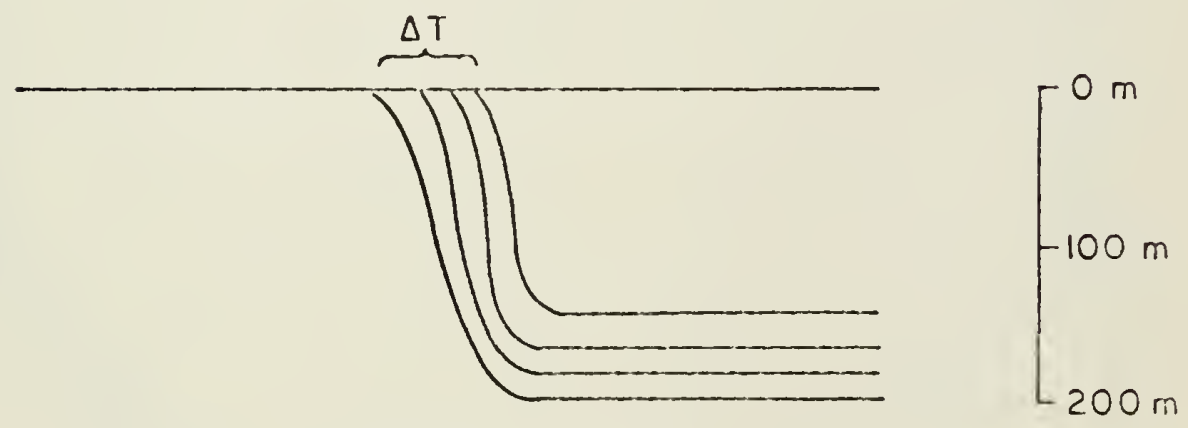

FIGURE $26(C)$

FIGURE 26

SCHEMATIC. THERMAL STRUCTURE ACROSS A CURRENT (A) SHALLOH MIXING - NO RESULTANT CHANGE. (B) SAME THERMAL STFUCTURE WITH DEEPER MIXING. (C) RESULT OF DEEP MIXING. 


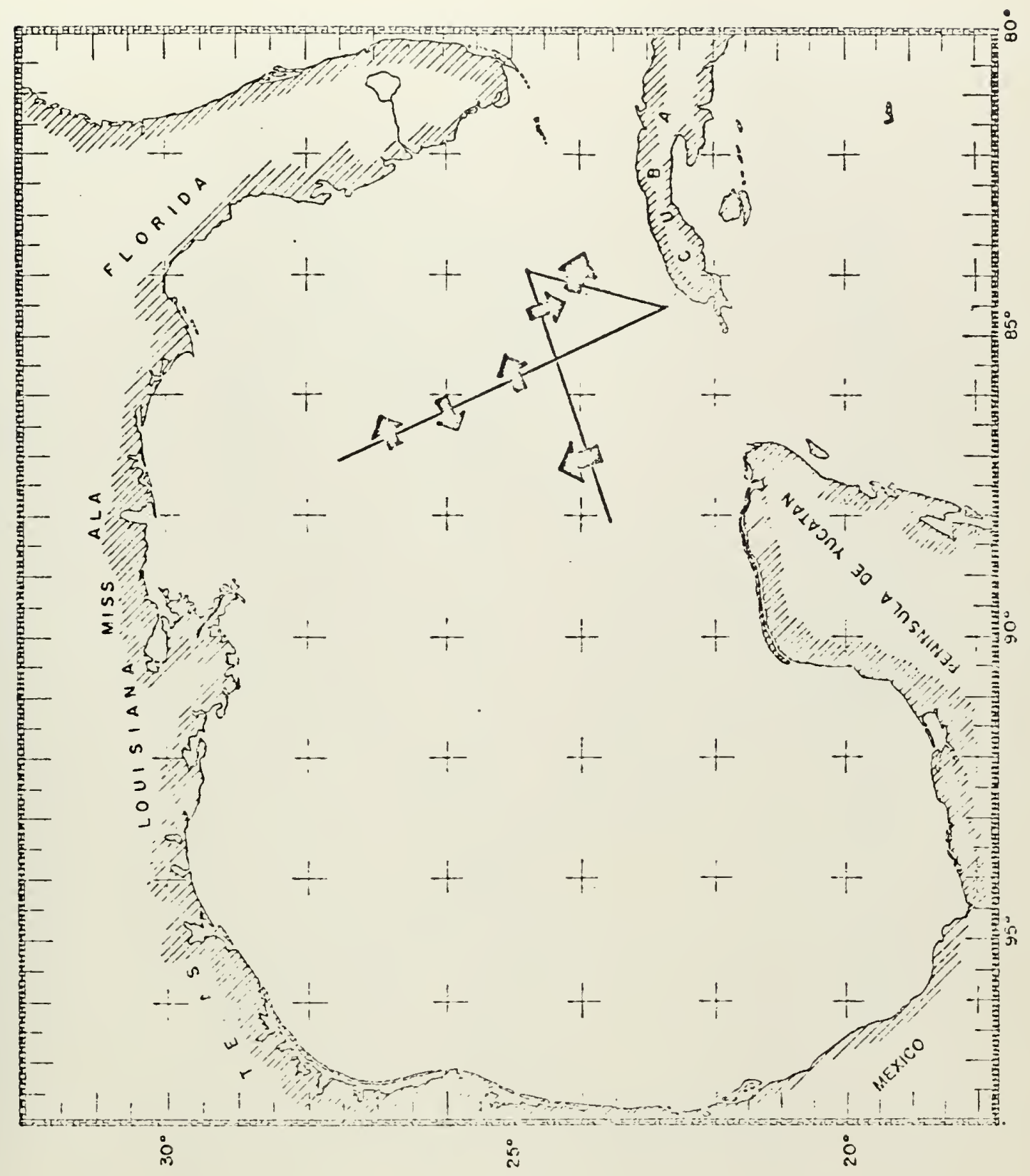

FIGURE 27

INTERPRETATION OF GULF LOOP CURRENT: WINTER 1966. 


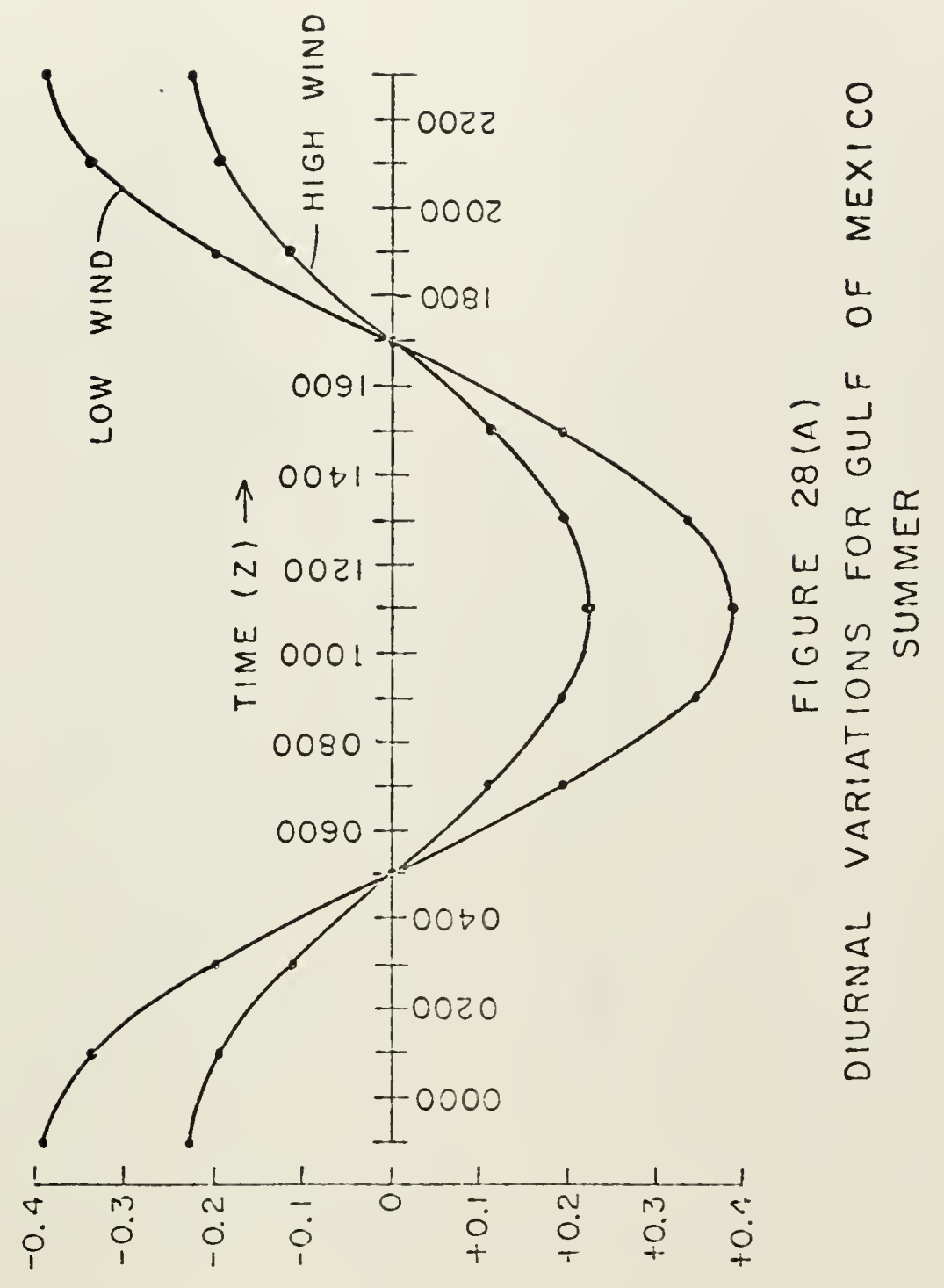




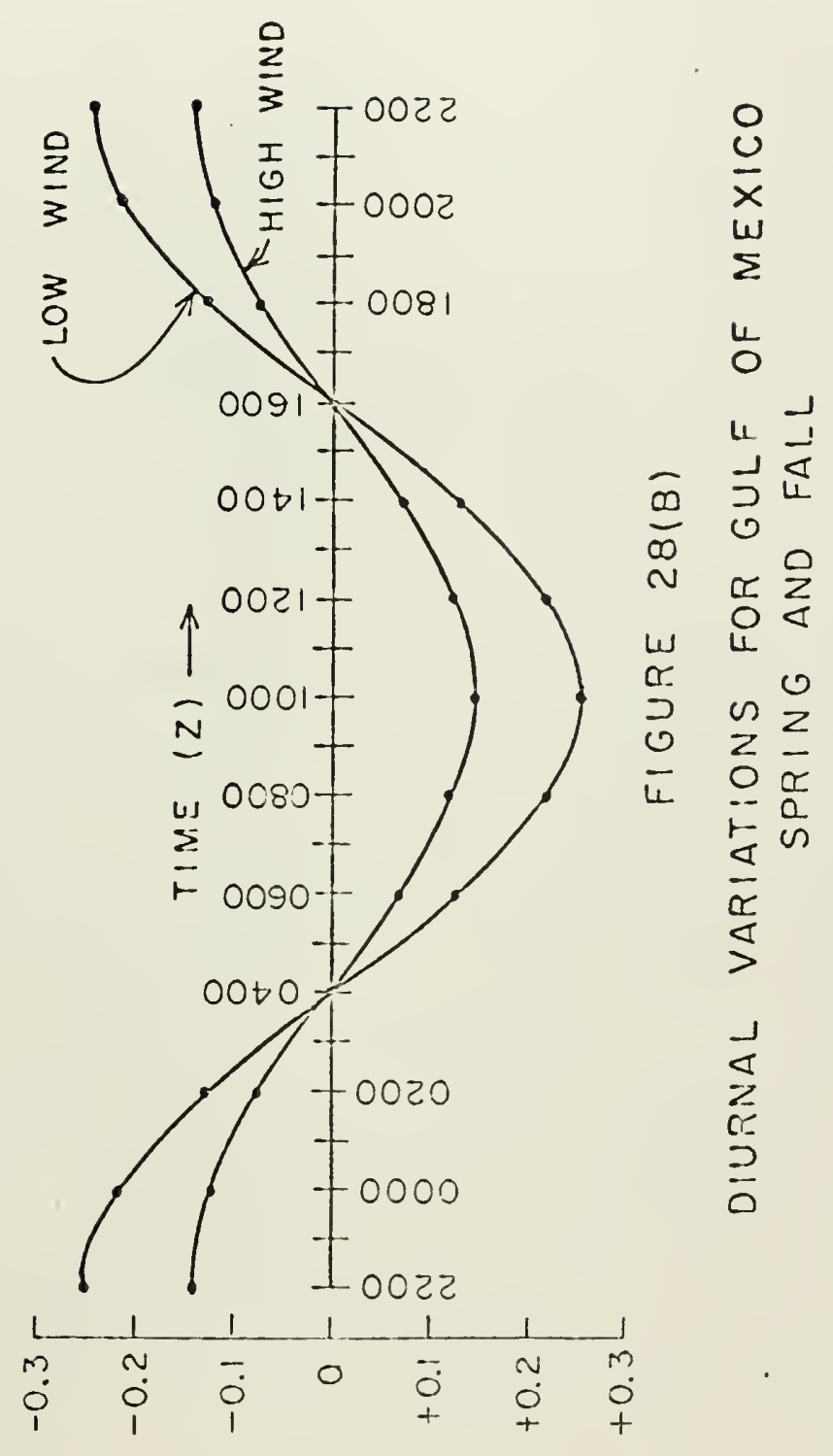




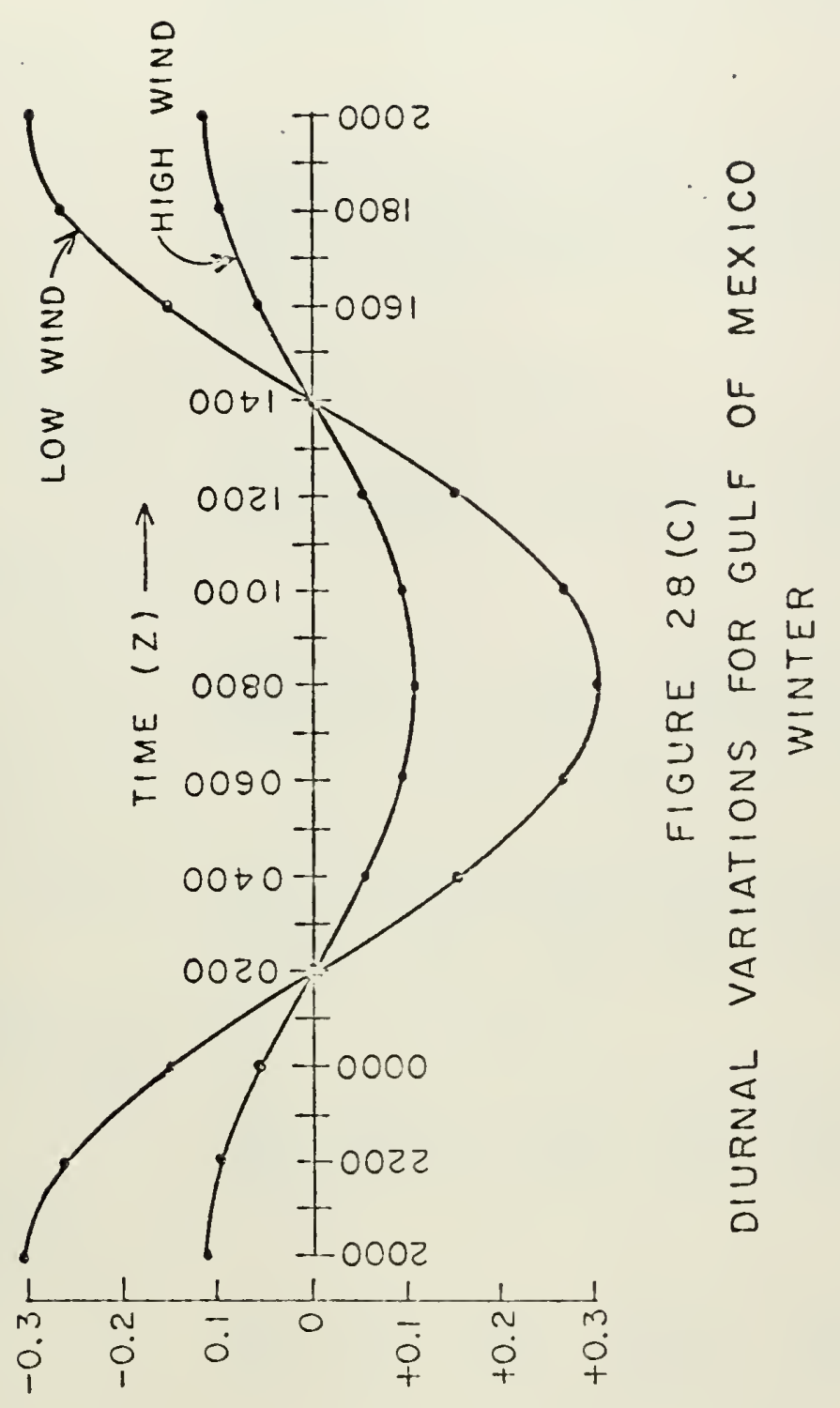




\section{REFERENCES}

Church, P. E.

1937 Temperatures of the Western North Atlantic from Thermograph Records, Assoc. D'Ocean. Physique, Publication Scientifique No. 4.

Cochrane, J. D.

1966 The Yucatan Current, Upwelling off Northeastern Yucatan, and Currents and Waters of Western Equatorial Atlantic, Texas A \& M Research Foundation Progress Report 66-23T, Project 286.

Deacon, E. L. and E. K. Webb

1962 Smal1 Scale Interactions, The Sea, Vol. I, Interscience Publishers, New York.

Engler, R. G.

1963 Data Sources for Surface Current Observations, NavOceano Informal Manuscript No. 0-63-63.

Ford, W. L., J. R. Longard, and R. E. Banks

1952 On the Nature, Occurrence and Origin of Cold Low Salinity Water along the Edge of the Gulf Stream, Jour. Mar. Res., 11:281-293.

Ford, W. L. and A. R. Miller

1952 The Surface Layer of the Gulf Stream and Adjacent Waters, Jour. Mar. Res., 11:267-280.

Francis, J. R. D.

1951 The Aerodynamic Drag of a Free Water Surface, Proc. Roy. Soc. London, A205:387-406.

Fuglister, F. C. and L. V. Worthington

1951 Some Results of a Multiple Ship Survey of the Gulf Stream, Tellus, 3 . 
Fuglister, F. C. and A. D. Voorhis

1964 A New Method of Tracking the Gulf Stream, Limnology and Oceanography, 10: (supplement, Nov. 1965) RI15-RI24.

Gibson, B. W.

1962 Sea Surface Temperature Synoptic Analysis, ASWEPS report 非 7 , NavOceano.

Iselin, C. O'D. and F. C. Fuglister

1948 Some Recent Developments in the Study of the Gulf Stream, Jour. Mar. Res., 7:317-329.

James, R. W.

1965 A Quantitative Evaluation of ASWEPS Sea Surface Temperature and Layer Depth Charts, NavOceano Informal Manuscript No. 0-39-65.

1966a Accuracy of Sea Surface Temperature Analysis --Part I, NavOceano Informal Manuscript No. $66-15$.

1966b Accuracy of Sea Surface Temperature Analysis --Part II, NavOceano Informal Manuscript No. 66-18.

1966c Ocean Thermal Structure Forecasting, ASWEPS Manual No. 5, USNavOceanO.

Koizumi, M.

1956 Researches on the Variations of Oceanographic Conditions in the Region of Ocean Weather Station EXTRA in the North Pacific Ocean (IV), Papers Meteorol. Geophys., Tokyo, 7:322-326.

LaFond, E. C.

1949 The Use of Bathythermograms to Determine Ocean Currents, Trans. Amer. Geophys. Union, 30: $231-237$.

Lee, A.

1959 Some Observations on the Structure of the West Spitzbergen Current, International Oceanographic Congress, Sept. 1959. 
Malkus, J. S.

1962 Large Scale Interactions, The Sea, Vol. I, Interscience Publishers, New York.

Mosby, $\mathrm{H}$.

1958 Variation diurne de la temperature de surface Centre Delge d'Oceanogr. et de Rech. Sous-Mar., Journees des 24 et 25 Fevrier 1958, pp. 165173 .

NavOceano

1963 General Comments Concerning the Preparation and Reliability of ASWEPS Sea Surface Temperature Charts, Forecasting Branch, Oceanographic Prediction Division, July 1963.

Peloquin, R. A.

1961 Implementation of an Airborne Oceanographic Platform, NavOceano Informal Manuscript No. 18-61.

1963 Airborne Radiation and Infrared Thermometers --Part II, NavOceano Informal Manuscript No. $0-16-63$.

Rol1, H. U.

1965 Physics of the Marine Atmosphere, Academic Press, New York and London.

Spilhaus, A. F.

1940 A Detailed Study of the Surface Layers of the Ocean in the Neighborhood of the Gulf Stream with the Aid of Rapid Measuring Instrurements, Jour. Mar. Res. 3(1):51-75.

Stomme1, H.

1947 Note on the Use of T-S Correlation for Dynamic Height Anomaly Computations, Jour. Mar. Res. 6(2): 85-92. 

Strack, S. L.

1953 Surface Temperature Gradients as Indicators of the Position of the Gulf Stream, Woods Hold Oceanographic Institute, Reference No. 53-53.

Sverdrup, H. U., M. W. Johnson, and R. H. Fleming

1942 The Oceans, Prentice Hal1, Englewood Cliffs,

von Arx, W. S. and W. S. Richards on

1953 The Surface Outcrop of the Gulf Stream Front, Woods Hole Oceanographic Institute, Reference No. 53-24.

Wilkerson, J., R. Peloquin, and I. Perlroth

1963 Airborne Radiation Thermometer Survey Tongue of the Ocean 5-9 February 1963, NavOceano Informal Manuscript No. o-20-63. 






thesC416

Sea surface temperature as an indicator

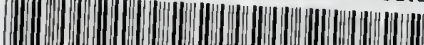

in

32768002097594

DUDLEY KNOX LIBRARY 